University of Windsor

Scholarship at UWindsor

\title{
The effects of an emotional disclosure writing task on the physical and psychological functioning of children of alcoholics.
}

\author{
Melanie Dawn. Gallant \\ University of Windsor
}

Follow this and additional works at: https://scholar.uwindsor.ca/etd

\section{Recommended Citation}

Gallant, Melanie Dawn., "The effects of an emotional disclosure writing task on the physical and psychological functioning of children of alcoholics." (2001). Electronic Theses and Dissertations. 3912. https://scholar.uwindsor.ca/etd/3912

This online database contains the full-text of PhD dissertations and Masters' theses of University of Windsor students from 1954 forward. These documents are made available for personal study and research purposes only, in accordance with the Canadian Copyright Act and the Creative Commons license-CC BY-NC-ND (Attribution, Non-Commercial, No Derivative Works). Under this license, works must always be attributed to the copyright holder (original author), cannot be used for any commercial purposes, and may not be altered. Any other use would require the permission of the copyright holder. Students may inquire about withdrawing their dissertation and/or thesis from this database. For additional inquiries, please contact the repository administrator via email (scholarship@uwindsor.ca) or by telephone at 519-253-3000ext. 3208. 


\section{INFORMATION TO USERS}

This manuscript has been reproduced from the microfilm master. UMI films the text directly from the origiral or copy submitted. Thus, some thesis and dissertation copies are in typewriter face, while others may be from any type of computer printer.

The quality of this reproduction is dependent upon the quality of the copy submitted. Broken or indistinct print, colored or poor quality illustrations and photographs, print bleedthrough, substandard margins, and improper alignment can adversely affect reproduction.

In the unlikely event that the author did not send UMI a complete manuscript and there are missing pages, these will be noted. Aso, if unauthorized copyright material had to be removed, a note will indicate the deletion.

Oversize materials (e.g., maps, drawings, charts) are reproduced by sectioning the original, beginning at the upper left-hand comer and continuing from left to right in equal sections with small overtaps.

Photographs included in the original manuscript have been reproduced xerographically in this copy. Higher quality $6^{*} \times 9^{*}$ black and white pholographic prints are available for any pholographs or illustrations appearing in this copy for an additional charge. Contact UMI directly to order.

ProQuest Information and Leaming 300 North Zeeb Road, Ann Abor, MI 48106-1346 USA 800-521-0600

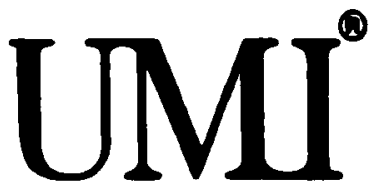





\title{
The Effects of an Emotional Disclosure Writing Task
}

on the Physical and Psychological Functioning of Children of Alcoholics

by

Melanie Gallant

\author{
A Thesis \\ Submitted to the Faculty of Graduate Studies and Research \\ through Psychology \\ in Partial Fulfillment of the Requirements for \\ the Degree of Masters of Psychology at the \\ University of Windsor
}

Windsor. Ontario, Canada

2001

C 2001 Melanie Gallant 
National Library of Canada

Acquisitions and Bibliographic Sorvices

305 Wellinoton Street Othme ON KIA ONY Caneda
Broliotheque nationale du Canada

Acquiaitions of sonvices bibliographiques

305. ru Welington

Oumen ON KIA ON

Cencia

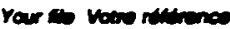

our to Novernimes

The author has granted a nonexclusive licence allowing the National Library of Canada to reproduce, loan, distribute or sell copies of this thesis in microform, paper or electronic formats.
L'auteur a accordé une licence non exclusive permettant à la Bibliotheqque nationale du Canada de reproduire, prêter, distribuer ou vendre des copies de cette thèse sous la forme de microfiche/film, de reproduction sur papier ou sur format électronique.

L'auteur conserve la propriété du droit d'auteur qui protège cette thèse. Ni la thèse ni des extraits substantiels de celle-ci ne doivent être imprimés ou autrement reproduits sans son autorisation. 


\begin{abstract}
The present study investigated the effects of an emotional disclosure writing task on the physical and psychological functioning of preteen and adolescent children of alcoholics $(\mathrm{N}=53$ ). It was hypothesized that writing about stressful events would have significant physical and psychological health benefits. Physical and psychological health were assessed with measures of strength and difficulties. internalizing symptoms, affect, and physical symptoms. These measures were administered at baseline and again at follow-up. Participants were randomly assigned to one of three conditions: an emotional writing group $\left(\mathrm{N}_{1}=18\right)$ who wrote about their thoughts and feelings with respect to stressful events, a non-emotional writing group $\left(N_{2}=19\right)$ who wrote descriptions of non-emotional events, or a non-writing control group $\left(N_{3}=16\right)$. Participants in the writing groups wrote for a period of 25 minutes on each of three consecutive days. There was evidence that the intervention was effectively executed as the essays written by participants in both the emotional and non-emotional conditions differed significantly in content in the hypothesized ways. Contradictory to the major hypothesis. emotional disclosure failed to convey any additional health benefits. A general improvement was found for all groups over time on internalizing symptoms, affect, and physical symptoms. Analysis of gender and age differences uncovered some noteworthy findings. The current study indicated that it is beneficial to have young people participate in studies in which they are given an opportunity to think about how they act and feel.
\end{abstract}




\section{Table of Contents}

Abstract $\ldots \ldots \ldots \ldots \ldots \ldots \ldots \ldots \ldots \ldots \ldots \ldots \ldots \ldots \ldots \ldots \ldots \ldots \ldots \ldots \ldots \ldots \ldots$

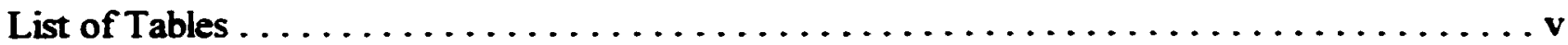

List of Figures $\ldots \ldots \ldots \ldots \ldots \ldots \ldots \ldots \ldots \ldots \ldots \ldots \ldots \ldots \ldots \ldots \ldots \ldots \ldots$

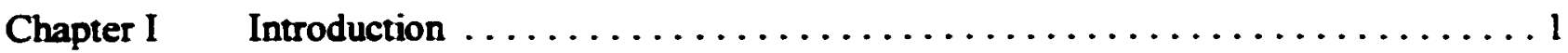

Theoretical Framework $\ldots \ldots \ldots \ldots \ldots \ldots \ldots \ldots \ldots \ldots \ldots \ldots \ldots$

Review of the Literature $\ldots \ldots \ldots \ldots \ldots \ldots \ldots \ldots \ldots \ldots \ldots \ldots \ldots \ldots$

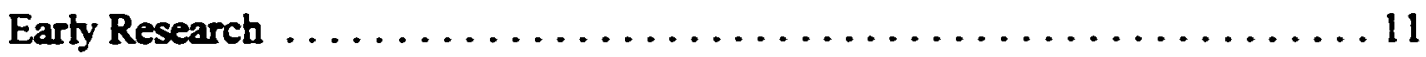

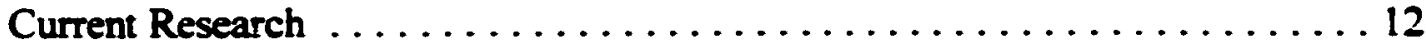

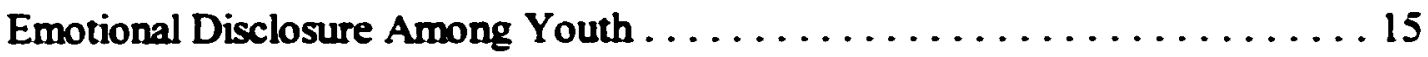

Chapter II Current Study

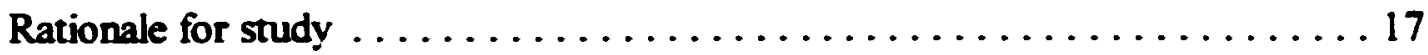

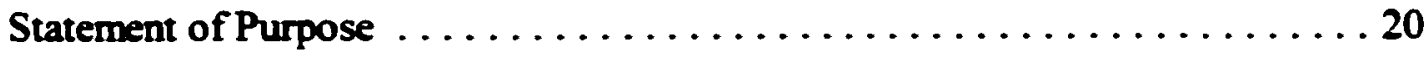

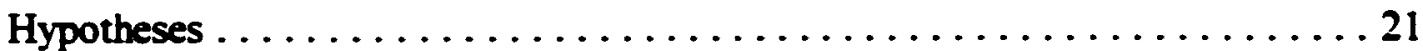

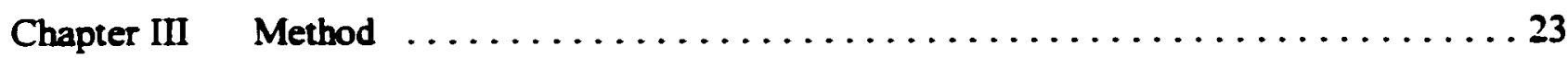

Participants . . . . . . . . . . . . . . . 23

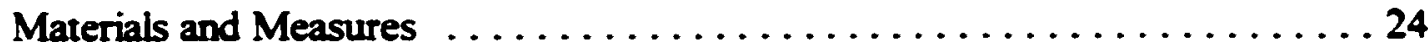

Procedure ................................... 29

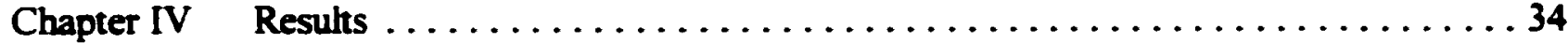

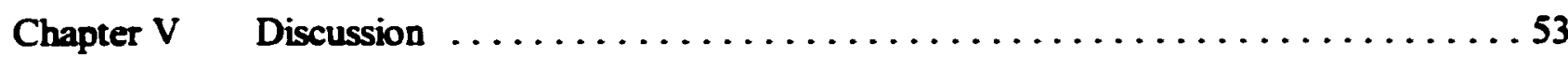

Qualitative Content of Essays . . . . . . . . . . . . . . . 61

Limitations . . . . . . . . . . . . . . . . . . 64

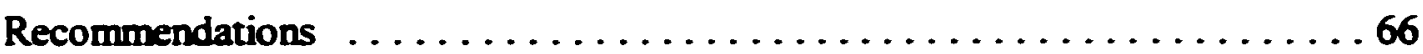

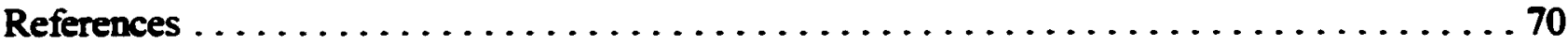

Appendix A: Participant Demographic Questionnaire . . . . . . . . . . . . . . 79

Appendix B: Parental Demographic Questionnaire $\ldots \ldots \ldots \ldots \ldots \ldots \ldots \ldots \ldots$

Appendix C: Children of Alcoholic Screening Test $\ldots \ldots \ldots \ldots \ldots \ldots \ldots \ldots \ldots \ldots \ldots$ 
Appendix D: Impact of Event Scale $\ldots \ldots \ldots \ldots \ldots \ldots \ldots \ldots \ldots \ldots \ldots \ldots \ldots \ldots \ldots \ldots$

Appendix E: Subjective Evaluation of Essay $\ldots \ldots \ldots \ldots \ldots \ldots \ldots \ldots \ldots \ldots \ldots \ldots$

Appendix F: Internalizing Symptoms Scale for Adolescents $\ldots \ldots \ldots \ldots \ldots \ldots \ldots$

Appendix G: Positive and Negative Affect Scale $\ldots \ldots \ldots \ldots \ldots \ldots \ldots \ldots \ldots$

Appendix H: Strength and Difficuties Questionnaire $\ldots \ldots \ldots \ldots \ldots \ldots \ldots \ldots \ldots$

Appendix I: Pennebaker Limbic Languidness Scale $\ldots \ldots \ldots \ldots \ldots \ldots \ldots \ldots$.

Appendix J: Participant Assent/ Parental Consent Forms for Control Group . . . . . . . . 92

Appendix K: Participant Assent/ Parental Consent Forms for Writing Groups . . . . . . . 94

Appendix L: General Participant Instructions . . . . . . . . . . . . . . . . 96

Appendix M: Experimental Writing Group Instructions $\ldots \ldots \ldots \ldots \ldots \ldots \ldots \ldots$ 


\section{List of Tables}

Table

Page

1 Demographic Characteristics of the sample and Sub-groups.

2 Physical and Psychological Measures: Mean Scores at Baseline and Follow-up. 40

3 Mean Values for Subjective Essay Content by Condition. 41

$4 \quad$ LIWC Content Analysis of Writing Products. 45

5 Comparison of Mean Affect Across all Three Writing Sessions. 47 


\section{List of Figures}

Figure

Page

1 Two Path Inhibition-Confrontation Model.

2 Revised Two Path Inhibition-Confrontation Model. $\quad 6$

3 Mean Excitement Score as a Function of Time and Writing Condition. 48

4 Mean Shame Score as a Function of Time and Writing Condition. 48

$5 \quad$ Mean Upset Score as a Function of Time and Writing Condition. 49

6 Mean Physical Symptoms Score as a Function of Gender and Time. 52

7 Mean Affect Score as a Function of Age Category and Time. 52 


\section{Chapter I}

\section{$\underline{\text { Introduction }}$}

Exposure to stress and trauma are inevitable aspects of life. Both directly and indirectly influence physical and psychological functioning (Taylor. 1999), and such influence is largely determined by an individual's subjective response to the stress or trauma. Emotional inhibition or the conscious suppression of one's thoughts and feelings with respect to personally stressful or traumatic experiences has been shown to compromise physical and psychological functioning (Greenberg, Wortman \& Stone, 1996a). Alternatively, emotional disclosure or the expression of one's thoughts and emotions with respect to personally stressful or traumatic experiences has been linked to enhancement of physical and psychological functioning (Pennebaker, 1995).

While the relation between stress. emotional disclosure and health has long been noted. it has not been until recently that researchers have taken an interest in studying the precise nature of this relationship. This has been due in large part to evidence suggesting that many psychological and physical disorders stem from unresolved experiences of stress and trauma (Pennebaker. 1985). In addition. new knowledge in the fields of neuropsychology, physiological psychology, and psychoneuroimmunology have suggested that the degree of physical, and/or psychological harm caused by stress and trauma is partly determined by an individual's emotional responses (Carison. 1999). There is new physiological evidence which suggests that a coping response such as emotional disclosure plays a direct and important role in reducing the negative effects associated with aversive or traumatic events and experiences. Consequently, a burgeoning area of research in the past decade has sought to understand the relation between stress, emotional 
disclosure and health as well as to devise unique methods of intervention which enable individuals to confront, cope with, and understand events of a personally stressful or traumatic nature.

Emotional disclosure is not a new concept. Jourard (1971) took a vested interest in the concept of self-disclosure which he defined as the process by which individuals reveal themselves to others. Such revelation was hypothesized to be essential to physical and emotional health and well-being (Jourard, 1959). Initially, the study of disclosure focused on the therapeutic relationship. In this sense. research focused on variables which influenced self-disclosure among clients. The aim was to find ways to facilitate and enhance self-disclosure within the therapeutic relationship. More recently, studies have begun to focus on natural patterns of self-disclosure in daily functioning; and such studies have revealed that self-disclosure is a fundamental human need (Rawlings. 1983).

Expressive writing defined as conscious revelation in the form of writing about personal and emotional topics (Pennebaker. 1989. 1990. 1993) has become a popular means of emotional disclosure within the last decade. Consequently, researchers bave systematically examined the ways in which writing about thoughts and feelings regarding personally stressful or traumatic experiences can influence mental and physical health. For instance, in a unique writing task designed and popularized by Pennebaker (1989), people wrote about their thoughts and feelings with respect to a personally stressful or traumatic experience or about superficial topics over a number of days. The assumption here was that individuals are able to unloosen and write about their deepest thoughts and feelings regarding stressful or traumatic events they have experienced in their lives.

Emotional disclosure carried out using this and other similar methods has proven to render 
a wide range of beneficial health outcomes both in the short and long term (Smyth. 1998). These have included: enhanced immune functioning (Pennebaker, Kiecolt-Glaser \& Glaser, 1988), increased positive affect (Paez, Velasco, \& Gonzalez, 1999), reduced visits to health care facilities (Pennebaker, Colder, \& Sharp, 1990), greater cognitive assimilation (Pennebaker. 1993), and decreases in blood pressure and heart rate (Pennebaker, Hughes, \& OHeeron, 1987). That such a simple emotional writing task could have such a profound impact on physical and psychological functioning is indeed both intriguing and worthy of further investigation.

For the most part. such studies investigating the effects of emotional disclosure in this way have used participants drawn from bealthy adult populations, the majority of whom were college student samples (Smyth, 1998). Few studies have investigated this technique with populations known to be at significant risk for, or suffering from psychological or physical disorders (Bootzin. 1997). In addition. few have examined its use with populations in need of, or currently receiving, therapeutic interventions. Consequently, it is uncertain whether writing can be used as a valuable and effective clinical intervention tool. There is lack of evidence to conclude that writing can actually serve as a substitute for, or supplement to, psychotherapy (Pennebaker. 1997b). Future research on writing about emotional experiences with clinically identified populations as well as populations currently receiving clinical interventions seems warranted.

Children of alcoholics are a population often identified as living in stressful home environments and being at increased risk for experiencing trauma. In fact, parental alcoholism has been categorized as a chronic condition that places undue stress on the offspring of alcoholics (Roosa. Beals, Sandler, \& Pillow, 1990). Examples of such stressors include: parental conflict, lack of emotional support, fear of violence or separation, and constant unresolved tension (Brown 
\& Lewis, 1999). Children of alcoholics have also been targeted as being more prone to experience major stressful life events such as parental divorce and remarriage, sexual, physical and emotional abuse, and changes in residence (Moos \& Bilings, 1982; Schulsinger, Korp, Goodwin, Teasdale, \& Mikkelson, 1986). Over time. exposure to these stressors has been shown to negatively influence the physical and psychological development of such children (Sher, 1991).

In addition to the increased likelihood of being exposed to stress and trauma, children of alcoholics are often characterized as a population among which emotional expression is often suppressed. In fact. they are frequently described as living by rather punitive rules which prohibit talking, trusting, and feeling (Black. 1982). Although such children do experience a broad range of feelings from love and happiness to loneliness and fear, in general, such feelings tend to be withheld (Lawson \& Lawson. 1998). Over time. the denial or suppression of emotion often becomes a learned response that is difficult to change (Nuechterlein, 1993). This emotional restraint has been linked to adverse physical and psychological outcomes (Robinson \& Rhoden, 1998).

\section{Theoretical Framework}

Results obtained from studies on emotional disclosure have prompted the use of theories to help explain the apparent positive relationship between the processing of emotions and health. Recently, Pennebaker (1989) devised a theory to explain how writing or verbalization of traumatic or stressful events improves physical and psychological health (Refer to Figure 1 for an illustration of this theoretical model). This theory has two tenets, one involving the 


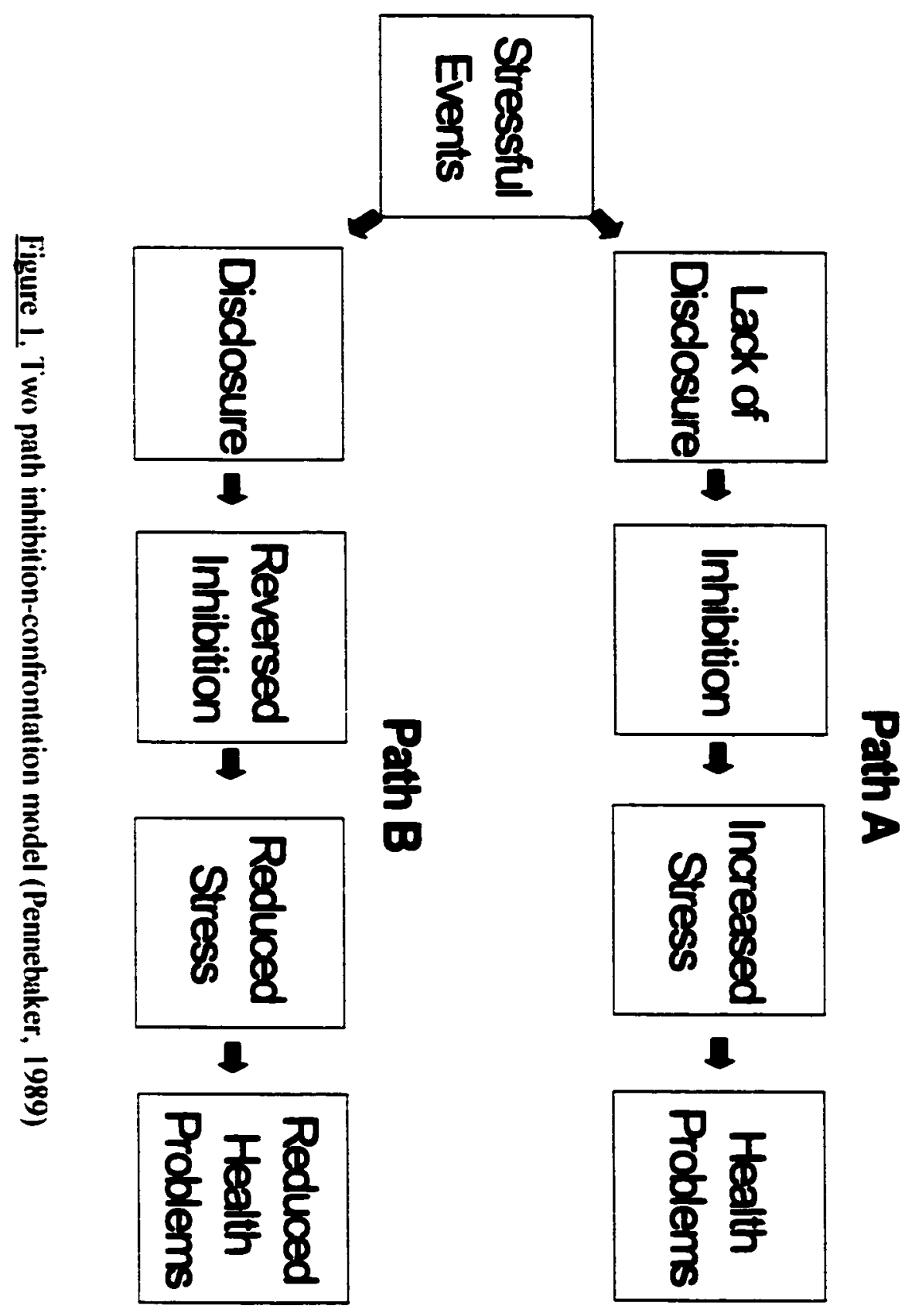




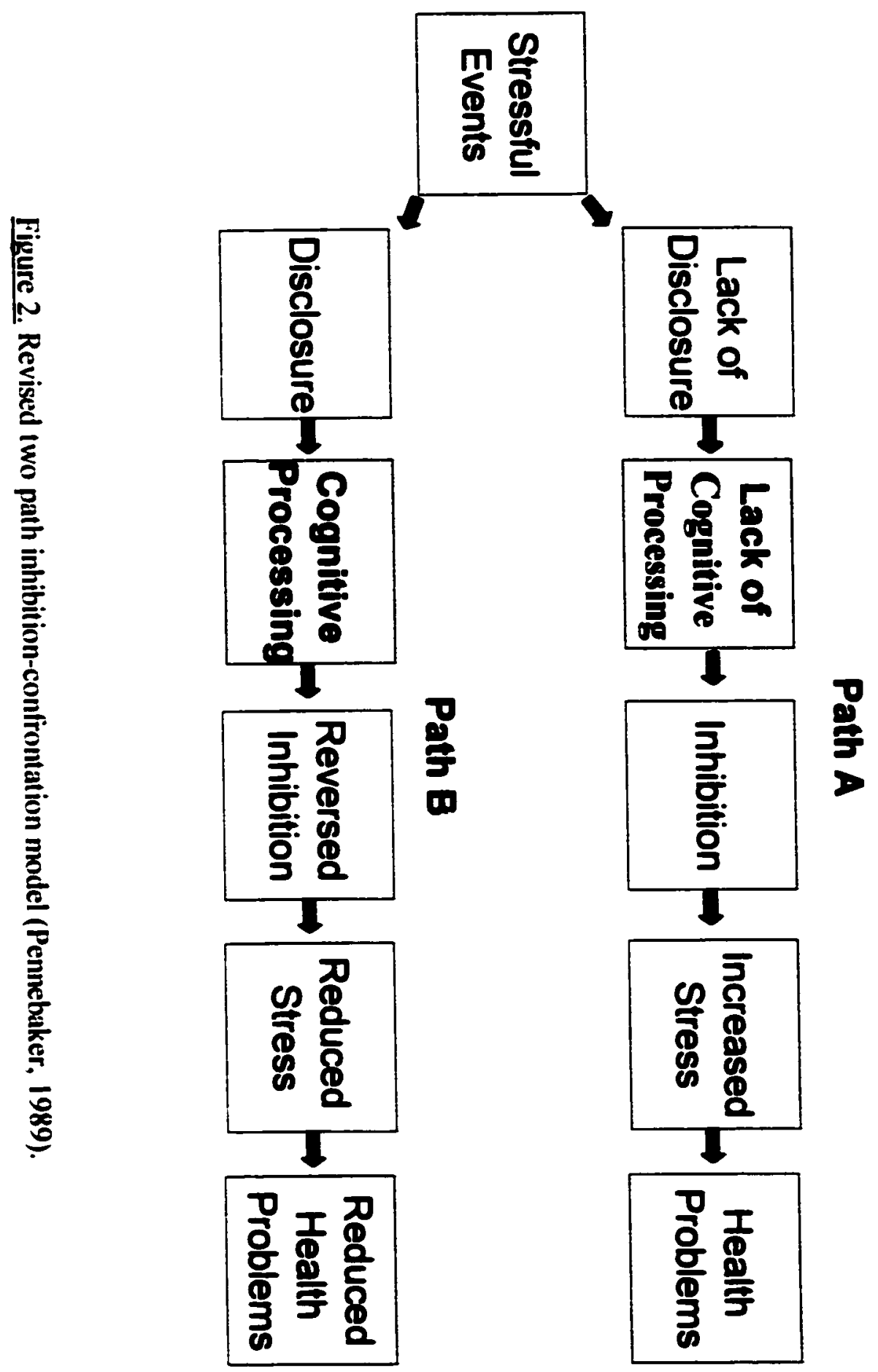

$a$ 
concept of inhibition and the other cognitive confrontation. The theory relies on an inhibitionconfrontation approach to explain why and how emotional disclosure bolsters physical and psychological health (Pennebaker, 1982; Pennebaker \& Beall, 1986). Basically, the theory posits that the inhibition of emotions is detrimental to an individual's health, whereas the ability to express emotions is beneficial to an individual's health.

Originally, Pennebaker (1989) theorized that the act of inhibiting thoughts or feelings (Figure 1) involves strenuous physical and psychological work which. over time. has a negative impact on the body. According to this theory, inhibition is defined as conscious or unconscious attempt to keep feelings, emotions or thoughts from being released. In this sense, inhibition can be considered a self-imposed restraint which interferes with the normal homoeostatic operations of the human body, producing both short and long term consequences.

In the short run, inhibition has been found to increase sympathetic arousal (Wegner, Shortt. Blake. \& Page, 1990), to magnify emotionality (Wegner \& Zanakos, 1994), and to increase physiological activity (Purdon, 1999). Over time, inhibition can come to constitute a chronic stressor on the body which increases susceptibility to physical and psychological illness (Seyle. 1976). As such, inability or lack of opportunity to release feelings or emotions, constitutes a risk factor in the etiology of stress-related disorders or illnesses.

Pennebaker's original inhibition theory has received substantial support. For example. it has been found that women with breast cancer who inhibited their emotions and attempted to conceal their illness evidenced lower remission rates and higher recurrence rates (Schwartz, 1990). Chronic inhibition of emotion has even been implicated in the development of cancer (Bonanno \& Singer, 1990; Taylor, 1999). Other studies have shown that concealing one's sexual 
identity (Cole, Kemeny, Taylor, \& Visscher, 1996), refusing to speak about the death of a spouse (Pennebaker \& O'Heeron, 1984), and harboring memories of childhood sexual abuse (Rubenstein, 1982) are all associated with negative health outcomes.

While Pennebaker's original theory received support, there was a lack of conclusive evidence to suggest that disclosure itself was responsible for causing the observed health benefits noted (Pennebaker, 1997a). This suggested that writing about a traumatic event may improve health. but not by reversing inhibition. Uncertainties with respect to the mechanisms underlying the relationship between emotional disclosure and health led Pennebaker to expand upon his original inhibition theory (Bootzin, 1997) (Refer to Figure 2 for an illustration of Pennebaker's amended two path model). Subsequently, he proposed that emotional disclosure also has an effect on cognition. From a cognitive perspective then. not talking or writing about certain events prevents such events from being translated into language (Pennebaker, 1997b). As a result, the event remains cognitively unstructured and the assimilation and understanding of the experience fails to occur. In essence, language (through writing or speaking) is required in order for the individual to process the experience into a more clearly organized and simplified form (Pennebaker, Mayne, \& Francis, 1997).

An example illustrates the importance of cognition in the linguistic processing of traumatic or stressful events. In a study conducted by Krantz and Pennebaker (1995), students were asked to express their feelings through different modes. The three different modes of expression included body language, writing, or exercising, respectively. Only students in the writing group showed significant improvement in health and grade point average. Thus, it was concluded that the mere expression of a trauma (i.e. through body movements) is not sufficient to alter health 
Emotional Disclosure and Health 9

outcomes. It appeared that what was necessary was the translation of the traumatic experience into language. Thus, Pennebaker's amended theory (Figure 2) stated that the relationship between emotional disclosure and health was mediated by the cognitive task of translating experiences into language forms (Krantz \& Pennebaker, 1995). In essence, translating experiences into language was necessary for health gains.

Similarly, it has been suggested that confronting a stressful or traumatic event may aid an individual in the organization (Meichenbaum, 1977), assimilation (Horowitz, 1976), and understanding of the event (Silver \& Wortman, 1980). According to Pennebaker (1997b), cognitive processing of the stressful or traumatic event is necessary before health can be influenced. Emotional disclosure, then, is plausible as a method of reversing the short and long term effects of inhibition only if there is a cognitive component involved. The simple act of recounting the experience is not enough. In effect. confrontation "facilitates the assimilation or understanding of the event. which, over time. results in a reduced need to inhibit thoughts and behaviors related to the experience" (Pennebaker, Barger, \& Tiebout, 1989, p. 577).

From a cognitive standpoint, making an experience language-based allows people to fully process the experience. Confronting the traumatic or stressful event ultimately ensures that the cognitive work is accomplished. As a result, individuals are able to assimilate. find meaning, and gain insights about the emotional event they reveal in their writing. Thus, confrontation is seen as a mechanism that allows individuals to make sense of and reframe events (Paez. Velasco, \& Gonzalez 1999). This suggests that humans can better understand their emotions and feelings through the construction of stories or narratives (Bootzin, 1997).

The confrontation component of the inhibition-confrontation model has mainly been 
assessed through the analyses of text. In such analyses, written or spoken language has been analyzed noting the actual percentage of insight and causal words. Words such as 'realize'. 'understand', 'think', and 'consider' constitute insight words, whereas words such as 'cause'. 'effect', 'reason', and 'because' denote causal words. Such words are assumed to reflect the degree to which a person is able to organize their thoughts, feelings, and/or emotions (Pennebaker \& King, 1999). With the continued practice of verbalization or inscription, it is assured that the number of insight or causal words will increase. thereby indicating that an individual is forming a more organized, coherent, and understandable representation of the event in question (Pennebaker. Mayne. \& Francis, 1997). This assumption has received substantial support as evidenced in studies which have shown that those individuals who show a significant increase in insight and causal words over the course of writing sessions, also show the greatest improvement on various health related measures (Pennebaker \& King, 1999).

Based on this theoretical framework. the present study assumes that among children of alcoholics, the physical and psychological work required to suppress emotions. thoughts and feelings related to personally stressful or traumatic experiences is detrimental to their physical and psychological health. Further. disclosure or expression of these emotions, thoughts. and feelings allows for cognitive confrontation of the experience. a resulting decrease in physical and psychological work. and a subsequent assimilation and understanding of the experience. Thus, not talking about or confronting the major events and experiences associated with growing up in an alcoholic environment is viewed as a form of inhibition. Over time, such inhibition is viewed as cumulative placing undue stress on the physical and psychological systems of children of alcoholics. As a result, these children may be more susceptible to physical illnesses and 
Emotional Disclosure and Health 11

psychological disorders because they are more likely to inhibit their thoughts and feelings.

Confronting one's experiences by writing about them is proposed as a mechanism for buffering the assumed stress-related effects experienced by children of alcoholics and curtailing both the short and long-term effects of inhibition. In addition, enabling them to translate their experiences into language is suggested to be a mechanism whereby they can come to a better assimilation and understanding of the experiences and events that have been personally traumatic or stressful for them. Facilitating confrontation through the use of writing is one proposed method through which they may learn to reduce stress and enhance their ability to cope.

\section{Review of the Literature}

\section{Early Research}

One of the first systematic studies designed to assess if writing about stressful or traumatic events would reduce stress was conducted by Pennebaker \& Beall (1986). In their original experiment. college students were randomly assigned to write either about an emotional event or a non-emotional event. Specifically, participants either wrote about a traumatic event, about their feelings regarding a traumatic event. or about superficial topics. The overall purpose of this experiment was to evaluate whether writing about traumatic events would influence health as measured by visits to medical centers, physiological arousal and self-reported physical symptoms.

Their results suggested that those participants assigned to write about personally traumatic life events experienced short term negative affect and physiological arousal followed by long term decrease in medical visits and self-reported physical symptoms compared to control participants Pennebaker \& Beall. 1986). There were only slight differences in outcomes between those participants who wrote about their emotions related to traumatic events and those who wrote 
detailed descriptions about traumatic events. It should also be noted, however, that this preliminary study was limited by marginally significant results, a small number of participants. lack of manipulation checks, and confounding demand characteristics (Pennebaker \& Beall, 1986).

Consequently, the authors cautioned against any definitive interpretations of these results.

This original study was instrumental in triggering interest in the systematic study of emotional disclosure and health. As a result, numerous studies subsequently employed the original or variations of the original writing task developed by Pennebaker (Pennebaker \& Beall. 1986). In fact, a recent meta-analysis performed by Smyth (1998) uncovered a total of 19 valid and reliable studies that have systematically examined the impact of Pennebaker's experimental manipulation (Pennebaker \& Beall, 1986). Results from this analyses concluded that the writing task is a powerful tool in helping to bring about significant health benefits among healthy participants.

What was even more encouraging was the fact that the effect size of $d=.47$ reported was similar to those effect sizes found among other conventional therapies (e.g. psychodynamic therapy, family therapy) (Smyth. 1998).

\section{Current Research}

In terms of physical health numerous studies have examined the effects of writing about emotional experiences versus writing about superficial topics. In these studies, there has been a reliance on both objective and subjective physical measures. For example, some studies have shown significant reductions in physician visits after the experimental procedure (Greenberg \& Stone 1992; Greenberg, Wortman, \& Stone, 1996b; Pennebaker \& Francis, 1996), as well as decreases in self-reported physical illness symptoms (Richards, Pennebaker, \& Beale, 1995). In terms of physiological markers, the writing paradigm has been shown to significantly influence 
immune functioning as measured by t-helper cell response rates (Pennebaker. Kiecolt-Glaser, \& Glaser, 1988), Hepatitis B antibody levels (Petrie, Booth, Pennebaker, Davison, \& Thomas, 1995), and skin conductance and heart rate (Pennebaker, Hughes, \& O'Heeron. 1987). In summary, the emotional disclosure writing task has proven to have a demonstratable effect on many physical health measures.

To examine effects on psychological health, most studies have used standardized selfreport measures of distress. anxiety, and affect as indicators of psychological functioning. Results with respect to such measures have not been as strong as those evidenced by physical outcome measures. In fact. in some of the studies employing affect measures, the results have been mixed, with some reporting significant effects on these parameters as a result of the writing experiment (Greenberg \& Stone. 1992; Greenberg, Wortman, \& Stone, 1996a), and others reporting no effects at all (Pennebaker \& Francis, 1996; Petrie, Booth, Pennebaker, Davison, \& Thomas, 1995). Although there seems to be conflicting evidence as to the psychological benefits of writing, Smyth (1998) concluded that writing about emotional topics plays a significant role in reducing distress. Additional studies that examine the psychological benefits of writing could help to resolve the current debate with respect to this issue.

Recently, there has been an interest in studying the ways in which writing about personally stressful or traumatic events alters cognitive functioning. Such studies are based on the notion that writing changes the way people represent stressful or traumatic events in their memory or consciousness (Pennebaker, 1993). It has been suggested that through writing, over a period of time, people come to a better assimilation and understanding of the event about which they write. Studies on emotional disclosure designed to examine cognition have typically relied on the 
Emotional Disclosure and Health 14

analyses of text using a comprehensive text analyses programme designed by Pennebaker \& Francis (1999). In these studies, it was found that the essays of people who evidence the greatest overall physical and psychological health improvements consistently showed a distinct pattern of word use. The pattern entailed greater use of negative emotion words, recurrent expression of anxiety, sadness, and a gradual increase in the number of cognitive words (i.e.. understand, realize, because, and reason). The increase in cognitive words was considered a sign that cognitive assimilation and understanding of the stressful or traumatic event is occurring to some extent (Pennebaker, 1993). More recently, it has been suggested that cognitive changes over time with respect to a personally stressful or traumatic events are significant predictors of psychological well-being (Smyth, 1998).

While having people write about their thoughts and feelings seems to result in various positive effects. there are some issues of concern that should also be noted. One of the plaguing concerns is that studies have yet to examine specific symptoms or physical or psychological parameters (Bootzin, 1997). Instead, the bulk of research here has examined overall changes in health associated with emotional disclosure. Thus, it is uncertain as to whether the emotional disclosure writing technique is capable of producing changes in a specific targeted symptom or an area of functioning (i.e. depression. anxiety, and specific physical symptoms).

Similarly, many of the results of existing studies cannot be readily generalized to other specific populations. Some criticisms of previous research have noted that the majority of these studies have been conducted on healthy adult and college student samples (Bootzin, 1997). Consequently, it is unclear whether their findings can be applied to other 'non-healthy' populations (e.g. those with physical or mental ilnesses, those suffering from terminal diseases, or 
in need of or currently involved in therapeutic interventions). Similarly, their generalizability to younger samples has yet to be determined. One neglected population in which the emotional disclosure writing paradigm has yet to be thoroughly examined is that of young people between the ages of 10 and 17.

\section{Emotional Disclosure Among Youth}

Springer and Pennebaker (1995) first conducted an emotional disclosure study on children. They investigated the effects of emotional disclosure of unpleasant events on physical health. The study involved children from grades 3 through 8 (ages 8-14 yrs), who were randomly assigned to one of two groups, who wrote about their thoughts and feelings regarding disturbing events that had occurred to them in the past (disclosure group), and the other who wrote about neutral topics (control group). The participants wrote one essay a day for a period of three consecutive days.

Their results suggested that children in grade 6 showed the best improvement in bealth status as measured by decreased absenteeism. It was also found that children in grades 6-8 used more negative emotion words and fewer positive words with each writing session (Springer \& Pennebaker. 1995). This was consistent with other findings (among adults), which have shown an increase in negative emotion immediately following each writing session (Smyth. 1998). Previous findings suggested that those participants who expressed a greater degree of sad or angry words and other negative expressions showed the greatest improvement in health when assessed at least one month after the cessation of the writing sessions (Pennebaker, 1993).

A recent study involving children. conducted by Reynolds, Brewin and Saxton (2000), was attempted to replicate Springer and Pennebaker's (1995) study. It involved adapting the 
Emotional Disclosure and Health 16

above study for school children of different ages, and in different British school systems (i.e. public versus private). The intent was to examine the effects of an emotional disclosure technique for coping with stress as measured by psychological and behavioral indices. These researchers hypothesized that school children who gave repeated descriptions of negative events in their writing would show the greatest improvement on measures of health, attendance, and school performance.

Their study involved a 12-group factorial design: 2 (inner city vs. suburban) $\times 3$ (emotional writing vs. non-emotional writing vs. non-writing control) $\times 2$ (primary school vs. secondary school). The sample ranged in ages from 8-11 in the primary group and 12-13 in the secondary group. During their experiment, children wrote for 15-30 minutes on three consecutive days and were measured on both physical and psychological parameters. Their results of this study were not as promising as those obtained by Springer and Pennebaker (1995). Specifically, there was no evidence of differences between the emotional and non-emotional writing groups in terms of either physical and psychological well-being. In fact, both groups evidenced a reduction in anxiety, physical symptoms. and difficulties experienced in school and at home.

One limitation of the Reynolds et al., (2000), study was the exclusive reliance on selfreport measures. Many of the positive effects of emotional disclosure have been attained using more standardized and objective measures of health and immune functioning (for example, see Greenberg, Wortman, \& Stone. 1996b; Petrie, Booth. Pennebaker, Davison. \& Thomas, 1995; Pennebaker et al, 1988). In summary, the dearth of, and mixed results from, emotional disclosure studies involving children precludes any definitive conclusions regarding the potential use of writing as a method of improving their physical and psychological well-being. 
Despite these limitations, the general consensus that writing about personally stressful or traumatic experiences is both physically and psychologically beneficial has not been refuted. Smyth's (1998) meta-analysis reported that the combined effect size for the valid studies executed to date was significant enough to conclude that expressive writing has a powerful effect on health. An suggestion for future research has been the evaluation of the writing task as a potential intervention with specific populations known to be suffering from or at-risk for the development of psychological and physical problems stemming from past traumatic or stressful experiences. usch as the children of alcoholics (Smyth. 1998).

Rationale for Studv

Reynolds et al., (2000) reported that chronic exposure to stressful events has a deleterious effect even in the absence of any manifest signs. Although some children of alcoholics may appear resilient to the stressors and trauma often associated with growing up in an alcoholic home, such effects typically influence their development in negative ways. For instance. children of alcoholics are considered at higher risk for a breakdown when confronted with stressors later in life (Harter, 2000).

Adult children of alcoholics have been shown to experience psychological and physical distress stemming from childhood exposure to the alcoholic environment (Kashubeck. 1994). In fact. children raised in alcoholic homes who develop without intervention have been found to manifest impaired psychological functioning in adult life. Such impairment involves depression, anxiety, and somatization; diminished perception of control, self-esteem, and self-worth; difficulty with interpersonal trust, intimacy, and attachment; unhealthy behavioral patterns and substance abuse; and generalized distress and maladjustment (Harter, 2000). Currently, research 
Emotional Disclosure and Health 18

investigating the link between childhood exposure to alcoholism and subsequent patterns of abnormal functioning in adulthood are being conducted (Harter, 2000). What the literature does suggest, however, is that, on average, it is not until aduhthood that the effects of parental alcoholism fully manifest themselves.

Due to environmental circumstances which preclude the expression of emotion, children of alcoholics also tend to manifest their feelings and anxieties in both physical and psychological forms (Robinson \& Rhoden, 1998). As a result, somatic complaints such as headaches. difficulty sleeping, fatigue, nausea, stomach aches, and eating problems are more prevalent among this population (Steinhausen. Nestler, \& Huth, 1982). Such problems are not easily alleviated even after alcoholic parents receive treatment. In fact, children of recovering alcoholics also show greater incidence of allergies, anemia asthma, frequent colds or coughs, and weight problems compared to children from non-alcoholic homes (Moos \& Billings, 1992). This suggests that the overall inhibition of emotion compromises the physical well-being of such children.

These children are also more prone to experiencing psychological problems, e.g. poor selfesteem diminished perception of control ineffective coping skills. and interpersonal hardships are common characteristics of the psychological functioning of this population (Robinson \& $R$ hoden, 1998). While it is difficult to pimpoint is the exact cause of poor psychological functioning, as it has been suggested that exposure to chronic stress and emotional battering have a significant impact and play a significant role in this regard (Robinson \& Rhoden, 1998). Consequently, some children of alcoholics are in need of safe havens or emotional sanctuaries in which they can be free to express their feelings regarding events or experiences they deem stressful, and/or traumatic (Reinert. 1999). This is especially true for adolescent children who are aware of and able to 
understand complex emotions, and the situations which evoke such emotions (Harris, 1989).

Children of alcoholics have also been identified as a population which registers high on clinical scales of impairment. A recent review of the literature on this population highlighted major areas of clinical dysfunction (Russell. Henderson. \& Blume, 1985). For example, children of alcoholics have been noted to show greater levels of anxiety and depression: a higher incidence of affect, behavioral and personality disorders; deficits in cognitive processing: and lower selfesteem and self-worth. It has been suggested that the clinical symptoms displayed by this population make them potential candidates for clinical intervention (Emshoff \& Price. 1999).

There has been some growing concern with regard to the availability of effective modes of intervention designed to allow children of alcoholics opportunities to express their thoughts and feelings (McNamee \& Offord, 1994). Such interest has grown in light of the fact that interventions which specifically address their needs and enable them to cope more effectively are limited (McNamee \& Offord. 1994). Consequently, most children of alcoholics never receive any form of help. Even when alcoholic parents enter treatment this does not assure that their children's needs will be addressed (Booz-Allen \& Hamilton. 1974). In short. there is a need to both develop and evaluate intervention methods designed to help such children cope. There is considerable evidence to suggest that failure to engage in emotional disclosure in response to personally stressful or traumatic experiences is detrimental to health (Greenberg \& Stone, 1992). This seems especially applicable to this population who are more prone to experience stress and trauma and are less likely to express their thoughts and emotions with respect to such stress and trauma (Barerra. Li. \& Chassin. 1995). While the expressive writing technique developed by Pennebaker (Pennebaker \& O'Heeron. 1984) seems to offer a potentially useful and effective 
Emotional Disclosure and Health 20

intervention. the limited amount of research with clinically identified populations precludes any definitive conclusions. What is lacking is systematic research exploring the utility of writing about emotional experiences with distinct populations (Bootzin, 1997). In addition, outcome measures tailored to assess specific areas particular to distinct populations as opposed to general health measures are needed (Smyth. 1998).

\section{Statement of Purpose}

The main purpose of this study was to assess the effects of an emotional disclosure writing task on the physical and psychological functioning of children of alcoholics. It assessed the extent to which having them write about their thoughts and feelings regarding personally stressful events influenced areas of physical and psychological functioning pertinent to this population. A second purpose was to examine the extent to which writing can be effective in allowing children of alcoholics to confront, understand, and resolve issues which have been particularly stressful. In this respect. the study was designed to provide children of alcoholics with a coping resource that may help offset the negative effects often associated with growing up in an alcoholic environment.

The main study objective included replicating and extending research on the effects of writing on physical and psychological functioning. and examining the extent to which selfreported severity of the event influences outcomes. The study is unique in two ways: i) it is one of the few to systematically examine the effects of writing with a population at risk for a variety of physical and psychological problems, and ii) it is one of the first to systematically evaluate the potential use of writing as a method of intervention for children of alcoholics.

In order to meet the purposes and objectives outlined above, the researcher and her supervisor adapted the written emotional disclosure technique designed by Pennebaker (1989) and 
evaluated its impact on physical and psychological functioning. In order to accomplish this. children of alcoholics were randomly assigned to write about either their thoughts and feelings regarding personally stressful or traumatic events or descriptive essays about superficial events. The following hypotheses were tested:

1. Participants who write about their thoughts and feelings with respect to personally stressful events will show greater physical and psychological functioning over time as measured by affect. internalizing symptoms (i.e. depression. anxiety), strength and difficulties and symptoms of physical illness when compared to both participants who write about superficial events and those that do not write at all. This hypothesis is based on the results of existing studies on emotional disclosure which have found significant improvements in physical and psychological functioning for those who write about personally stressful experiences (Smyth 1998).

2. Participants who write about their thoughts and feelings with respect to personally stressful events will show gradual cognitive assimilation and understanding of the events they write about as evidenced by the use of more insight and causal words in their essays when compared to both participants who write about non-emotional topics and participants who do not write at all. This is based on the formulated hypothesis that the prolonged translation of psychological events into language facilitates personal understanding and insight by strengthening the representation of these events in memory or consciousness (Pennebaker, 1997a).

3. Participants who rate the events they choose to write about as more severe will likely show greater improvements in physical and psychological functioning, as indicated by 
Emotional Disclosure and Health 22

decreases in self-reported physical symptoms and internalizing symptoms and increases in positive affect. This is based on literature which suggests a positive association between depth of disclosure and health (Greenberg \& Stone, 1992).

Sub-group analyses will be conducted for both gender and age variables to test for significant differences between both females and males. No hypothesis will be made with respect to the non-writing control group. This is due to the fact that previous studies (Reynolds et al. 2000) failed to explore differences between the writing groups and the non-writing control groups. Thus, any differences at this point in time remain theoretically and empirically speculative. 
Emotional Disclosure and Health 23

\section{Chapter III}

\section{Method}

\section{Participants}

Sixty individuals between the ages of 10 and 17 who were self-identified as children of alcoholics were recruited for the study. For the purpose of this study, children of alcoholics were defined as those individuals aged seventeen or younger who were living, or had lived. with at least one alcoholic parent. as identified by the Children of Alcoholics Screening Test (CAST). These individuals were also selected based on their affiliation with a recognized treatment centre for alcoholism. Once identified, children were contacted and asked to participate. Enrollment took place on a rolling admission basis within a two month time period (December to February). Initially, 60 individuals consented to participate in the study. Of these individuals. 4 declined to partake when further contacted. 2 were declined due to the fact that upon learning about the nature of the study they felt uncomfortable and 1 participant could not be reached for follow-up assessment. Thus. a total of 53 participants completed the study.

Participants were randomly assigned to one of two writing conditions (emotional writing. $[N=20]$ vs. non-emotional writing, $[N=20]$ or a non-writing control condition $[N=20])$.

Participants in the emotional writing condition were instructed to write about their thoughts and feelings with respect to personally stressful events, while participants in the non-emotional writing condition were instructed to write about superficial events. A non-writing control group was included to control for the act of writing itself. All participants were treated in accordance with the ethical principles of the American Psychological Association and the Canadian Psychological Association. and the University of Windsor. 
Materials and Measures

\section{Demographic and Background Characteristics}

A brief questionnaire was used to assess demographic characteristics as well as relevant information specific to children of alcoholics (see Appendix A). Demographic information included: gender. age, ethnicity, socioeconomic status, marital status of parents, family position (youngest. middle. oldest child), and living arrangements (mother, mother and father, father. grandparent). Additional questions considered important to children of alcoholics included current involvement in support groups, current practice of journal writing, current or previous counseling or treatment for mental or psychological disorder (e.g. seeing a school counselor or psychologist), current or previous medical conditions or disabilities. and current prescribed medication. These data were subsequently used to determine and assess the influence of covariates.

A parental demographic questionnaire was also created to gather information considered pertinent to this study (See Appendix B). Demographic information considered relevant included: socioeconomic status. marital status. and ethnicity. Additional information included questions about whether their child had a learning disabilities. was involved in any therapeutic interventions. and was currently on any prescribed medication.

\section{Children of Alcoholics Screening Test (CAST)}

The Children of Alcoholics Screening Test (CAST) was developed by Jones (1983), in order to facilitate the identification of children who have experienced difficulties due to their exposure to alcoholic environments (see Appendix C). The CAST is a 30-item inventory measuring children's attitudes, feelings, perceptions, and experiences related to parental drinkingSome examples of items in the CAST inventory are: "Have you ever thought that one of your 
Emotional Disclosure and Health 25

parents had a drinking problem?", "Did you ever think your father/mother was an alcoholic?", "Do you ever resent when one of your parents' drinks?", etc. Items are answered dichotomously (either yes or no). The inventory is scored by adding up the number of 'yes' responses. A cutoff score of 6 on the CAST has demonstrated to be appropriate for the identifying children of alcoholics as such (Charland \& Cote. 1998). The CAST is appropriate for children ages nine and above.

Research on the CAST has supported the utility, reliability, and validity of this measure (Pilat \& Jones, 1985). Charland and Cote (1998) recently evaluated the CAST on a sample of young adolescents from intact alcoholic homes. The results revealed a high level of instrument homogeneity with a Cronbach alpha statistic of $\alpha=.89$ and a Spearman-Brown split half reliability coefficient of $\underline{I}=.90$. In summary, the CAST has proven to be a valid and reliable measure which is effective in identifying the offspring of alcoholics (Roosa, Sandler, Beals \& Short, 1988).

\section{Subjective Evaluation of the Event}

\section{The Impact of Events Scale (IES)}

The IES was developed to assess the severity of the subjective impact of stressful or traumatic events (Horowitz, Wilner, \& Alvarez, 1979). Specifically, it measured the degree to which a stressful or traumatic experience caused intrusion (e.g. disturbing experienced ideas, images, feelings, or bad dreams) and avoidance (e.g. consciously recognized avoidance of certain thoughts. feelings, or situations). The IES is a 15-item Likert-type scale rated on a 4-point scale ranging from "not at all" (1) to "often" (4). There are 7 items for intrusion and 8 items for avoidance. Participants are asked to think about a certain experience or event and rate how frequently they experienced each of the 15 items contained in the scale. Some examples of these 
Emotional Disclosure and Health 26

items include, "I thought about it when I didn't want to", "I had waves of strong feelings about it", and "pictures about it popped into my mind". Cronbach's alphas for this scale have ranged from $\alpha=.79$ to .92 for intrusion and from $\alpha=.82$ to .91 for avoidance (Zilberg, Weiss. \& Horowitz, 1982) (see Appendix D).

\section{Subiective Evaluation of the Essay (SEE)}

Participants were asked to rate on a 5-point scale ranging from "not at all" (0) to "a great deal" (4). on four items: i) the extent to which their essays were personal. ii) revealing of their emotions, iii) something which they have wanted to speak to others about, and iv) something which they have spoken to others about. Participants were also asked if they have actually experienced the event they wrote about ('yes' or 'no'). This evaluation measure was adapted from a questionnaire designed by Greenberg, Wortman, and Stone (1996a) to measure the subjective evaluation of an event. The questionnaire for this study was tailored for a youth population and was used as a manipulation check to see whether participants' perceptions of their writing corresponded with their writing instructions (see Appendix E).

\section{Psvchological Functioning Measures}

\section{Internalizing Symptoms Scale for Adolescents (ISSA)}

The ISSA is a standardized. norm-referenced scale developed to assess adolescent's selfperceptions of internalizing symptomatology, the broad range of emotional, cognitive, and physiological symptoms associated with depression, anxiety, somatic problems. social withdrawal, and various types of affect (see Appendix F). This is a self-report instrument for use with adolescents by revising the Internalizing Symptoms Scale for Children (ISSC) developed by Merrell. Crowley, and Watters (1997). The ISSA was developed by making the items on the ISSC 
more appropriate for the concerns and developmental level of adolescents. Forty items were also added to the adolescent version in order to better measure the areas of positive affect, somatic problems, and worry. It contains 63 items and uses a 4-point Likert-type rating scale. where $1=$ 'Never True' and $4=$ 'Often True'. The instrument has been used to assess behavioral, social and emotional functioning among adolescents. Reliability coefficients based on two concurrent validity studies have been found in the range of $\alpha=.90$ for this measure (J. W. Merrell, personal communication. October. 16. 2000). Overall, the measure appears to be an acceptable identifier of symptoms that are common across internalizing syndromes.

\section{Positive and Negative Affect Scale (PANAS)}

The 20-item PANAS was developed by Watson, Clark, and Tellegen. (1988) as a brief and accurate measure of positive and negative affect. Essentially, it is used to measure the primary dimensions of mood: positive affect and negative affect. This scale contains $\mathbf{2 0}$ mood descriptors (e.g. active. excited. hostile) which characterizes either positive or negative affect (see Appendix G). The 10 PANAS items assessing positive mood plus the 10 items assessing negative mood are summed to yield separate NA and PA scores. Cronbach alpha reliabilities for this measure range from $\alpha=.86$ to .90 for positive affect and $\alpha=.84$ to .87 for negative affect based on administration over a period of one year (Watson et al.. 1988).

\section{Linquistic Inquiry and Word Count (LIWC)}

All essays were analyzed with the computerized text analysis program. Linguistic Inquiry and Word Count (LIWC) (Pennebaker \& Francis, 1996, 1999). This program was designed to analyze text files based on the percentage of words that reflect positive emotion negative emotion, causation, and insight or self-reflection (Pennebaker, Mayne, \& Francis, 1997). This is 
one of the first language analysis programs to capture the personal and psychological personality of each respondent. Correlations between LIWC word category inclusions and judges' ratings have been reported as $\underline{\underline{r}}=.68$ for negative affect words, $\underline{\underline{r}}=.64$ for positive affect words, and $\underline{r}=$ .77 for insight words (Pennebaker, Mayne \& Francis, 1997).

LIWC is composed of a dictionary of over 2,200 words and root words which are linked to a variety of categories characterizing language composition, psychological processes, and current concerns (Pennebaker \& King, 1999). For example, within the psychological category there is an emotional sub-category composed of specific dictionaries for negative emotion word use. positive emotions, and so forth. The words selected for each category were chosen based on having judges independently match dictionary words with specific category words. For example. the word angry is identified as an emotion word.

The LIWC category of interest for this study were psychological processes. The intent of this category is to identify emotional. cognitive, sensory and social processes. For example, happy and love would be considered positive emotion words which tap favourable processes of affect. On the other hand. causal words such as because, reason, or why, reflect active thinking and are thus classified within the cognitive processes category. In this study, LIWC was used to assess the percentage of negative, positive, insight, causal, and self-reflective words. The amount of negative and positive words were used as an indicator of affect while the number of insight, causal, and self-reflective words were used as an indicator of cognitive assimilation. Overall, the text analysis was used as a means of providing a measure of affective and cognitive functioning. The Strengths and Difficulties Questiomaire (SDO)

The SDQ is a Likert-type self report scale that identifies areas of difficulty with respect to 
Emotional Disclosure and Health 29

social, behavioral, and emotional areas of functioning (see Appendix $H$ ). The scale consists of 25 items responded to on a 3-point scale of "not true" $(0)$, "somewhat true" (1) and "certainly true" (2). Items are totaled to provide an overall summed score and a score on five sub-scales (e.g. hyperactivity, emotional symptoms, conduct problems, peer problems, and prosocial functioning). Discriminant validity for this measure ranged from $\underline{\underline{r}}=.85$ to .87 (Goodman, 1997).

\section{Phvsical Functioning Measures}

\section{Pennebaker's Inventory of Limbic Languidness (PILL)}

The PILL consists of 54 common physical symptoms (Pennebaker, 1982, Appendix I).

The items are scored on a 5-point scale which rates the frequency of each symptom ranging from $1=$ "have never or almost never experienced the symptom", to $5=$ "experience the symptom more than once every week". Only the items that are responded to are scored and summed. The PILL has been shown to have adequate internal consistency with Cronbach alpha measures ranging from $\alpha=.88$ to .91 (Pennebaker. Burnam. Schaeffer. \& Harper, 1977). Test-retest reliability for this measure averaged across all 54 items has been calculated to be $\underline{r}=.73$ (Pennebaker et al. 1977). Overall. the PILL has been confirmed as a valid and reliable measure which is effective in tapping the frequency of occurrence of common physical symptoms.

\section{Procedure}

The names and telephone numbers of individuals between the ages of 10 and 17 whose parent(s) had been. or were currently, involved with a recognized treatment facility for alcoholism were obtained from this organization's client database. The potential participants included those individuals between the ages of 10 and 17 who were, at the time of the study, involved with a Children of Alcoholics Youth Program at Brentwood Recovery Centre in Windsor, Ontario. In 
addition. individuals in this age range whose parent(s) have been or are currently involved with the recognized treatment centre. Potential participants were first contacted to ascertain if they were willing to participate in the study. All interested participants were given offered an initial briefing on the study in which they were made aware of the time commitment and tasks involved in the study. With respect to the tasks involved, participants were notified that they might be asked to write about stressful events which had happened to them. Participants were also advised that the study may make them feel sad or blue. It was made clear that if they felt uncomfortable about writing about stressful experiences then they did not have to participate.

After making potential participants aware of the nature of the study, they were then asked if they would still like to participate. If they agreed, they were then asked to sign an assent form. Participants assigned to the writing groups (emotional and non-emotional writing groups) signed assent form $\mathbf{A}$ while participants assigned to the non-writing control group signed assent form $B$ (See Appendix J). Due to the fact that the population was between the ages of 10-17 parents were also asked to sign consent for allowing their child to participate (See Appendix K). Again, two forms of consent were used, one for the parents of children in the intervention group and another for those parents whose children were in the non-writing control group. A schedule for testing was then arranged to suit the time schedules of the participants.

Eligible and agreeing participants were randomly assigned to either an emotional writing group ( $\left.n_{1}=20\right)$, a non-emotional writing group $\left(n_{2}=20\right)$, or a non-writing control group $\left(n_{3}=20\right)$. Thus, this design attempted to control for the content of what was written as well as the act of writing process itself. Those participants assigned to the writing conditions were scheduled to come in for three consecutive days for $\mathbf{4 0}$ minute sessions in which they would write for $\mathbf{2 5}$ 
minutes and then fill out some questionnaires. The study was introduced to the writing group participants as involving journal writing. A definition and description of journal writing was given to these participants orally. [See Appendix $L$ for a detailed description of the general instructions which will be given to participants in both writing groups]. This protocol was based on a recent study by Reynolds et al., (2000), which used the diary of Anne Frank as a primer for the writing exercise. In this study, journal writing was used as the primer to help participants understand the purpose of and procedures for journal writing. The non-writing control group simply filled out preand post-test measures and did not engage in any form of writing.

Participants who were randomly assigned to the emotional writing group $\left(n_{1}=20\right)$, wrote about their thoughts and feelings regarding an event they had experienced which had been personally stressful (emotional group), while participants in the control group $\left(\mathrm{n}_{2}=20\right)$, wrote a description of a superficial and non-emotional event (non-emotional writing group). (Refer to Appendix $L$ for a detailed description of participant instructions for both the experimental and control groups). Again, the non-writing control group $\left(n_{3}=20\right)$ simply filled out pre and post-test measures and did not engage in any form of writing.

Each participant was given a code number to further ensure confidentiality. Participants were assured that anything they wrote would not be seen or marked by their parents, their peers or anyone involved in the treatment program at the recovery home. They were told however, that the primary investigator would read their essays. Thus. total anonymity was not assured. In addition, they were told that if the investigator felt that an essay indicated potential or actual physical or psychological harm (e.g.. suicidal thoughts or physical abuse) then the investigator 
Emotional Disclosure and Health 32

would contact the individual who wrote the essay to discuss the content of the essay, and that their parents would also be contacted and notified. The investigator would discuss appropriate referral sources with the individual and the parent in the event that professional help was warranted (e.g. Adolescent Crisis Service, Community Crisis Centre, Distress Centre). In addition. participants and parents were made aware of and given the names of trained program staff at the facility of interest who were available to address and deal with troubling or potentially harmful issues.

During the first writing session, participants were asked to fill out the Children of Alcoholics Screening Test (CAST), the Positive and Negative Affect Schedule (PANAS), the Internalizing Symptoms Scale for Children (ISSC), the Strengths and Difficulties Questionnaire (SDQ) and the Pennebaker Limbic Languidness (PILL) scale. In addition, participants filled out the demographic questionnaire. Participants were asked to fill out these pre-test measures as honestly as possible. When the participants had been briefed on the experimental proceedings and had filled out the appropriate questionnaires. participants in the emotional and non-emotional writing groups began their first writing session. In order to facilitate the writing experiment. participants wrote during scheduled times in separate rooms. The principal investigator was present at all times to facilitate the experimental procedure as well as address any participant questions or concerns.

Once participants had filled out the pre-test questionnaires they were told to begin writing. They were given 20 minutes of uninterrupted silence after which they were notified that they had 5 minutes left. When the 25 minutes were up, participants were given the IES questionnaire and a shortened version of the PANAS questionnaire. Participants were also asked to fill out an essay 
Emotional Disclosure and Health 33

evaluation form as well as indicate whether or not they had actually experienced the event which they wrote about in their essay. When this had been done, participants were reminded of the date and time for their next writing session. The same procedure followed for all subsequent writing sessions.

When participants had completed their three writing sessions, they were given a date and time to return in one month to fill out post-test measures. Such measures included the PANAS, ISSC. SDQ. and PILL. After the follow-up had been completed, debriefing occurred. During the debriefing participants were given a list of supportive services available on-site (Recovery Home for Alcoholics) as well as within the larger community (e.g. Adolescent Crisis Service, Community Crisis Centre, Distress Centre, Kid's Help Hotline, and Teen Health Centre). Part of the debriefing also included a discussion on the noted physical and psychological health benefits. both in the short and long run, of writing about events or experiences which have been difficult or stressful. All participants received a complementary journal as an incentive for journal writing continuation. In addition, a voluntary feedback form was offered to participants that allowed them to give qualitative feedback about the writing experience. Participants were then asked if they had any questions or concerns about the study, which were answered accordingly. 
Emotional Disclosure and Health 34

\section{Chapter III}

\section{Results}

Data were analyzed using SPSS for Windows, version 9.0. To begin, baseline comparisons were made between the three intervention groups (emotional writing, non-emotional writing, and non-writing control) using one-way analysis of variance (ANOVA) where applicable and chisquare tests where the data violated parametric test assumptions. Subsequent analyses were also performed using SPSS-X.

\section{Demographics}

A breakdown of these participants by demographic variables of interest was performed. $A$ complete listing of demographic characteristics for the entire sample pool as well as by experimental condition can be seen in Table 1. This table is based on non-missing items '. By gender, the pool of participants broke down to 28 males and 25 females. Age was divided into categories: the first category included ages $10-12(n=24)$, the second category ages $13-15(n=$ $20)$, and the third category ages $16-17(n=9)$. In terms of ethnicity, $72.9 \%$ of the participants were Caucasian while the remaining $\mathbf{1 8 . 9 \%}$ were Native Canadian.

I It must be noted that the missing values consistently noted for most demographic variables were a result of items omitted by a few cases. Thus, the omissions are not random, but a reflection of an isolated number of participants and/or parents who failed to provide answers on some of the demographic questions. 


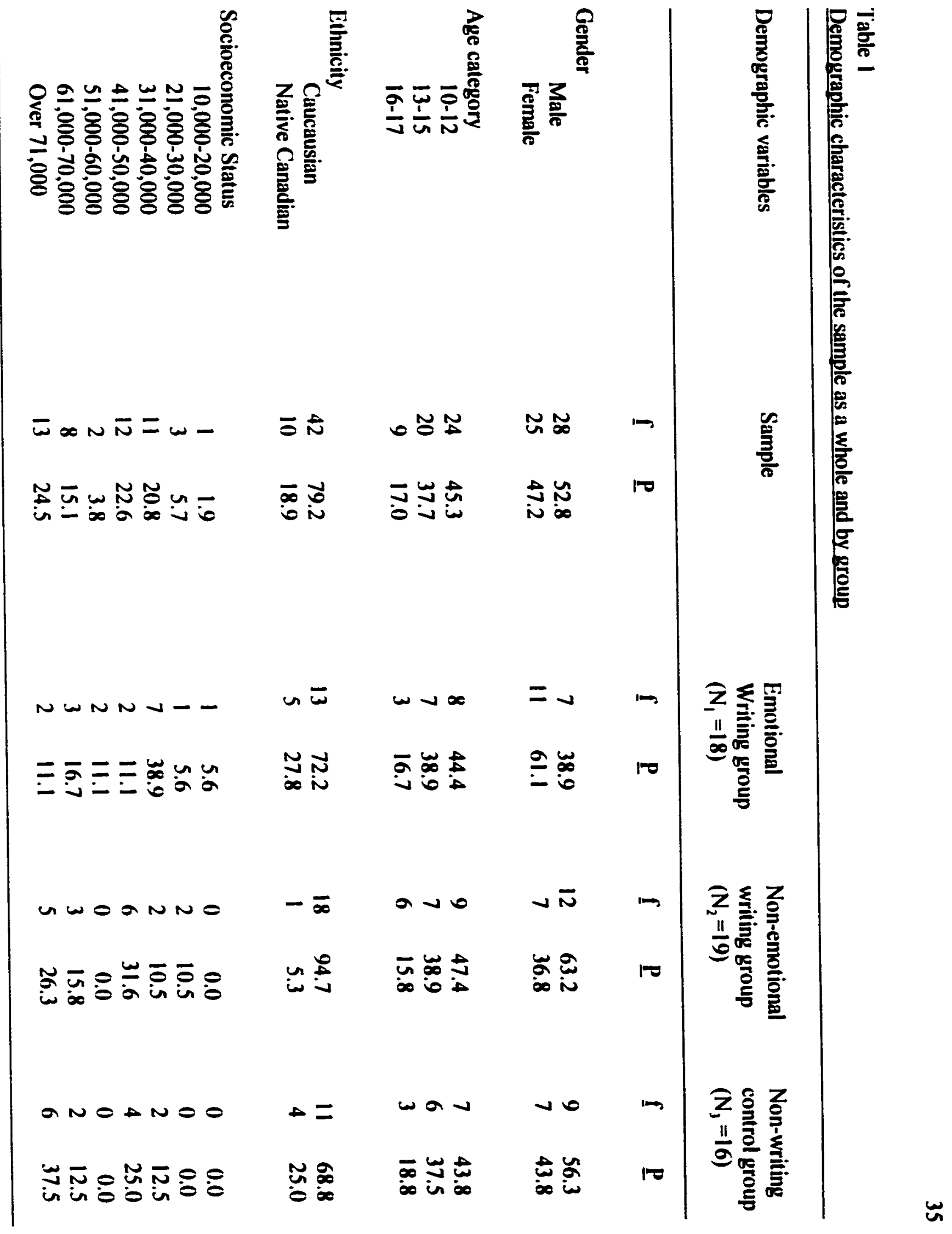




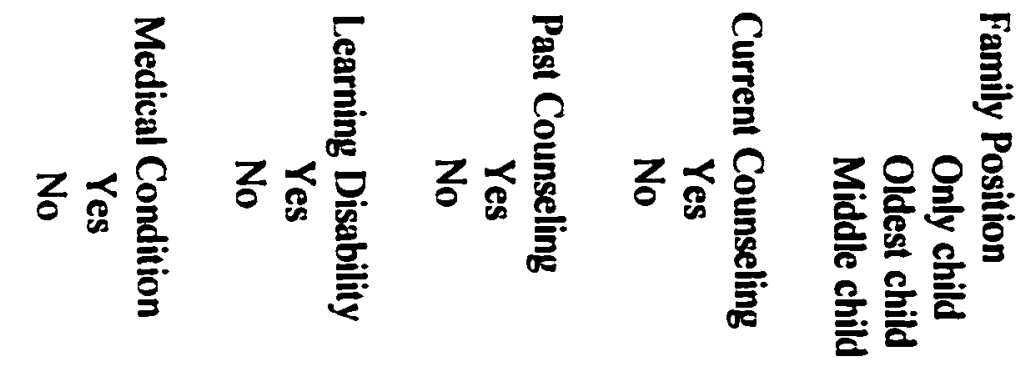

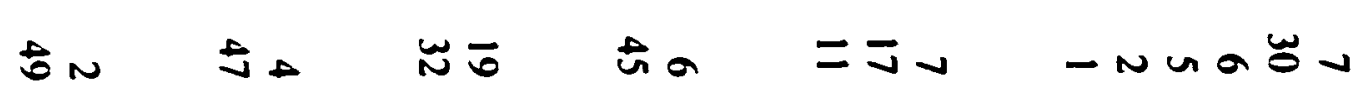

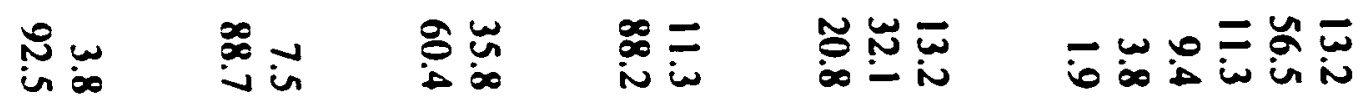

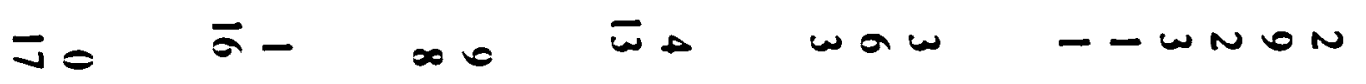

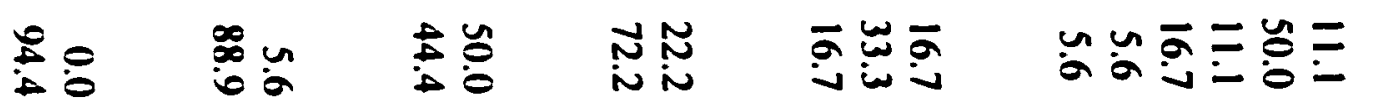

$\bar{E} \quad \bar{N}=\infty \quad \overline{0}$

$\operatorname{An}$

$00--\bar{\omega}$

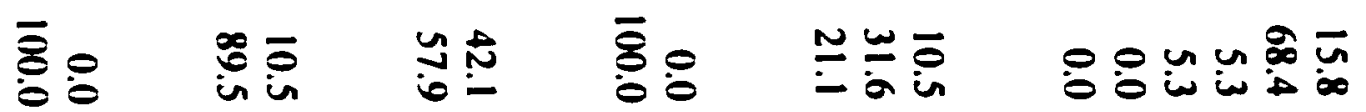

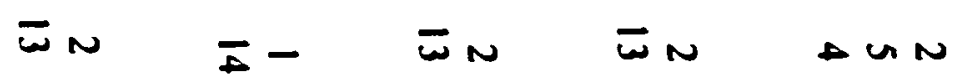

$0--\infty \infty n$

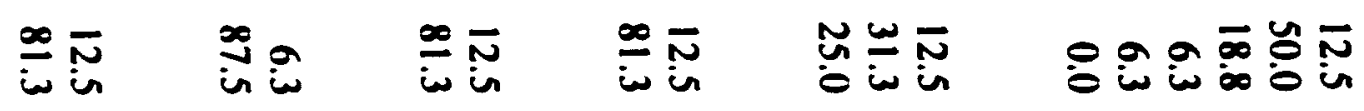

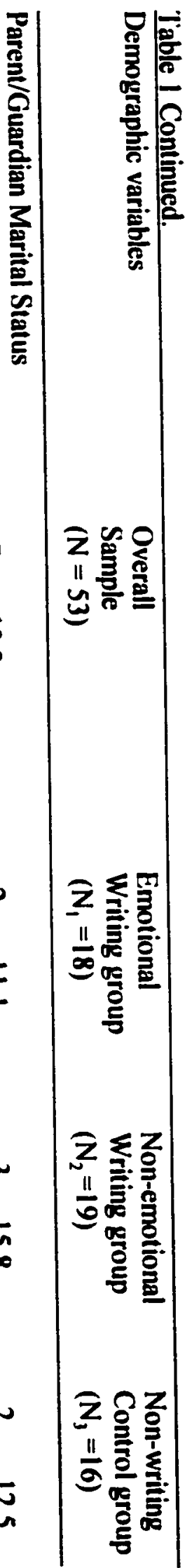


Emotional Disclosure and Health 37

In terms of socioeconomic status, $\mathbf{4 3 . 4 \%}$ of the participants came from homes with an annual income of between $\$ 30,000-\$ 50,000$. Of the remaining participants, $7.6 \%$ came from homes with an annual income of $\$ 30,000$ or less, $18.9 \%$ came from home with an annual income between $\$ 50,000$ and $\$ 70,000$ and $24.5 \%$ came from homes with an annual income of $\$ 70.000$ or more. In terms of parentalguardian marital status, $52.8 \%$ of participants reported that their parents were married, $32 \%$ reported that their parents were separated, $5.7 \%$ reported that their parents were remarried. and 9.4\% were unsure as to the marital status of their parents. Also, 52.8 $\%$ lived with both of their natural parents, $28.3 \%$ lived with only their mother, $9.4 \%$ with only their father. $7.5 \%$ with their remarried mother and stepfather and $1.9 \%$ with their grandparents. Thirty-two percent were the youngest children, $20.8 \%$ were middle children. $32.1 \%$ were oldest children. and $13.2 \%$ were only children.

In terms of both psychological and physical characteristics, the following were noted. Eighty-six percent were not receiving any type of counseling. Of the remaining $11.3 \%$ who were receiving counseling, it was either from a social worker, youth worker, or addiction counselor. Seven percent of the sample had been diagnosed with a learning disability and $3.8 \%$ with a medical condition.

There were no significant differences between the three intervention groups with respect to gender, $\chi^{2}(2)=2.29, \mathrm{p}>.10$, age, $\mathrm{F}(2,50)=.033, \mathrm{p}>.10$, socioeconomic status, $\chi^{2}(12)=$ 15.79, $\mathrm{p}>.10$, ethnicity, $\chi^{2}(2)=3.77 . \mathrm{p}>.10$, parent/guardian marital status, $x^{2}(10)=6.83, \mathrm{p}$ $>.10$, family position, $\chi^{2}(6)=.55, p>.10$, current counseling, $\chi^{2}(2)=4.84, p>.10$, past counseling, $\chi^{2}(2)=5.65, \mathrm{p}>.01$, learning disabilities, $\chi^{2}(2)=.31, \mathrm{p}>.10$, medical conditions, $\chi^{2}$ (2) $=4.99, \mathrm{p}>.01$, or diary keeping $x^{2}(2)=2.33, \mathrm{p}>.10$. This indicated that randomization was 
effective.

\section{Reliability of Measures}

The dependent variables were measured by strength and difficulties (SDQ), internalizing symptoms (ISSA), affect (PANAS), and physical symptoms (PILL). Reliability analyses (Cronbach's alpha) were performed on each of the dependent measures using SPSS. This yielded alpha coefficients of $\alpha=.76$ for the SDQ, $\alpha=.80$ for the positive affect subscale of the PANAS, $\alpha=.84$ for the negative affect subscale of the PANAS, $\alpha=.94$ for the ISSA. $\alpha=.93$ for the PILL, $\alpha=.95$ for the IES, and $\alpha=.76$ for shortened version of PANAS used pre-post writing session. Overall, there was a high degree of internal consistency found for each of the dependent measures.

\section{Measures at Baseline}

The three intervention groups were compared on all physical and psychological measures in order to identify any group differences at baseline. in all cases. The unadjusted means for all measures are shown in Table 2 . Since the subscales of the SDQ were significantly correlated, a MANOVA was run. A preliminary test of sphericity indicated that the assumption of sphericity had not been violated. A mutivariate analysis of variance on the five subscales of the strength and difficuhties questionnaire $(\mathrm{SDQ})$ revealed no overall group effect, $\underline{F}(1,52)=1.34 . \mathrm{p}>.10$. In addition, the two subscales of the PANAS measure showed no overall group effect, $\underline{F}(1,52)=$ $.27 . \mathrm{p}>.10$.

There were no gender differences found for any of the physical and psychological measures. Age differences were found on the positive affect subscale of the PANAS, $\underline{\operatorname{P}}(2,50)=$ $4.64, \mathrm{p}<.01$. Univariate tests showed that this was attributable to those in both the $10-12$ and $13-$ 15 age categories scoring higher on positive affect compared to those in the 16-17 age category, 
Emotional Disclosure and Health 39

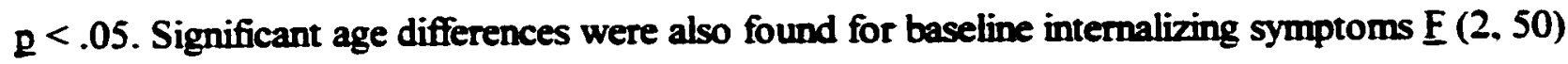

$=4.28, \mathrm{p}<.01$. Subsequent univariate tests showed that those in $16-17$ age category scored

significantly less on internalizing symptoms compared to both the 10-12 and 13-15 age categories.

\section{Experimental Writing Manipulation Checks}

\section{Subjective Evaluation of Essay Writing}

In order to assess whether participant's perceptions of their writing was consistent with the experimental writing instructions. participants rated their own essay on four items. These items included the degree to which participants thought their writing: (a) was personal, (b) revealed their emotions. (c) was something they had wanted to talk about. and (d) was something they had talked about with others (See page 25). For each item, a $2 \times 3$ (condition $\times$ writing session) mixed analysis of variance (ANOVA) was computed (refer to Table 3 for a summary of these results). Significant main effects were found for the degree to which the essays were rated as personal as well as the degree to which the essays were revealing of emotions. It was found that the emotional writing group rated their essays as more personal, $F(1,34)=30.76, p<.001$. and revealing of their emotions. $F(1.34)=31.28, \mathrm{~g}<.001$, compared to the non-emotional writing group. As expected. the emotional writing group reported describing and talking about their emotions significantly more than did the non-emotional writing group. There were no significant differences between the emotional and non-emotional writing groups with respect to the degree to which they had wanted to, or had. talked to others about the events they wrote about in their essays. Overall there were no main effects for time, nor were there any significant interactions. for any of the items on the subjective evaluation of the essay measure. 
Table 2

Physical and Psychological Measures: Mean Scores at Baseline (BL) and Follow-up (FL) (N=53)

The Three Conditions

\begin{tabular}{lll}
\hline Emotional & Non-emotional & Non-writing \\
Writing & Writing & Control
\end{tabular}

$\left(N_{1}=18\right) \quad\left(N_{2}=19\right) \quad\left(N_{3}=16\right)$

$B L \quad F U \quad B L \quad F U \quad B L \quad F U$

Measures Assessed

Strength and Difficulties

SDQ

Conduct

Emotional

Hyperactivity

Peer Problems

Total (exc. prosocial)

Prosocial

$\begin{array}{llllll}1.49 & 1.33 & 1.49 & 1.40 & 1.66 & 1.48 \\ 1.46 & 1.43 & 1.38 & 1.41 & 1.79 & 1.55 \\ 1.79 & 1.64 & 1.76 & 1.69 & 1.96 & 1.97 \\ 1.43 & 1.46 & 1.24 & 1.33 & 1.36 & 1.27 \\ 6.17 & 5.86 & 5.87 & 5.83 & 6.77 & 6.27 \\ 1.33 & 1.41 & 1.26 & 1.39 & 1.31 & 1.35\end{array}$

Internalizing Svmptoms

ISSA

$2.43 \quad 1.88$

$2.40 \quad 1.95$

$2.35 \quad 1.78$

Affect

PANAS

Positive Affect

Negative Affect
$2.33 \quad 2.16$

$2.93 \quad 2.95$

$1.72 \quad 1.37$
$2.18 \quad 2.25$

$2.66 \quad 2.97$

$1.71 \quad 1.55$
$2.19 \quad 2.25$

$2.74 \quad 2.95$

$1.63 \quad 1.54$

Physical Symptoms

PILL

$2.08 \quad 1.83$

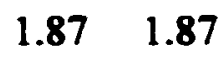

$1.85 \quad 1.64$ 
Table 3

Mean Values for Subjective Essay-Content by Condition (N=37)

$\begin{array}{ll}\text { Variables } & \text { Experimental } \\ \text { Assessed } & \text { Feelings } \\ & \left(N_{1}=18\right)\end{array}$

Writing Session

$\underline{\text { S1 }} \quad \underline{\mathbf{S}} \quad \underline{\mathrm{S}}$

Experimental

No-Feelings

$\underline{\mathbf{F}}$ $\left(\mathrm{N}_{2}=19\right)$

Essav-related dimensions

Personal

Reveal Emotion

Wanted to talk about

Had talked about

$\begin{array}{lll}4.41 & 4.22 & 4.11 \\ 3.88 & 3.56 & 3.78 \\ 2.47 & 2.56 & 2.39 \\ 2.76 & 2.22 & 2.83\end{array}$

$\begin{array}{lll}2.31 & 2.68 & 2.36\end{array}$

$30.76 *$

$\begin{array}{lll}1.53 & 2.21 & 2.21\end{array}$

$\begin{array}{lll}2.32 & 2.42 & 2.47\end{array}$

$\begin{array}{lll}2.11 & 2.05 & 2.37\end{array}$

$31.28 *$

0.01

1.27

Impact of Event Scale

IES

$\begin{array}{lll}2.36 & 2.35 & 2.46\end{array}$

$\begin{array}{lll}1.45 & 1.46 & 1.47\end{array}$

$17.04^{*}$

Note. S1: First Writing Session S2: Second Writing Session S3: Third Writing Session

$* \mathrm{p}<.001$ 
After each writing session, subjects also completed the IES questionnaire. The IES was used to assess the emotional impact of the writing topic. In order to evaluate whether significant differences existed among writing groups, a $2 \times 3$ (condition $\times$ writing session) mixed ANOVA was performed to test for differences across all three sessions. There was a main effect for condition $\underline{E}(1,34)=17.04 . \mathrm{p}<.001$, but no main effect across sessions and no interaction. The emotional writing group reported that the events they wrote about had more of an emotional impact on them compared to the non-emotional writing group. The emotional writing group reported that what they wrote about has been something which had significantly effected their thoughts and emotions compared to the non-emotional writing group.

The next issue examined was whether those participants who perceived the topic they wrote about as being severe would show greater improvement in physical and psychological functioning when compared to participants who rated the event they wrote about as being less severe. All participants who were assigned writing conditions were divided into severe and nonsevere groups on the basis of their IES score. A median split was performed on participants' average IES mean scores across all three writing days. Subsequently. a series of $2 \times 2$ (severity $\times$ time) mixed factorial ANOVA's were conducted for each of the dependent measures. With respect to internalizing symptoms. strength and difficulties, and physical symptoms, there were no significant interactions. The only main effect was on the internalizing symptoms scale, $F(1,34)=$ 10.87. $\mathrm{p}<.001$, where both groups showed a significant improvement over time. There was a significant interaction of group by time for positive affect, $F(1,34)=4.46, p<.01$, whereby, those who rated their essay topic as being high in emotional and cognitive impact decreased in positive affect over time, compared to those who rated their essay topic as low on impact. 


\section{Analysis of Writing}

In total. 111 essays were written, 54 written by the emotional writing group and 57 by the non-emotional writing group. The content of each essay was identified and subsequent categories of themes were established. This was done separately for each of the writing groups because the content between them differed significantly.

Of the 54 essays written by the emotional writing group, $56 \%$ dealt with family problems (parental conflicts; sibling conflicts; parental alcoholism; death of a parent or a family pet; separation/divorce/remarriage; family member illnesses; and 3\% past sexual abuse), $30 \%$ dealt with personal problems (self-esteem, suicide [self, friend, or family member]; anger; body image; loneliness); $26 \%$ dealt with friendship problems (fighting with friends; dating; sexual relationships); $24 \%$ dealt with school problems (fighting/bullying; general problems faced in school): $4 \%$ dealt with work problems.

Of the 57 essays written by the non-emotional group, $58 \%$ of the essays described school related activities and events: $16 \%$ described activities engaged in with friends; $12 \%$ described family activities: $9 \%$ described sports activities: $9 \%$ described future events or activities (e.g. upcoming Christmas party).

The percentages for both writing groups total more than $100 \%$ because many of the same topics were discussed during more than one session. Additionally, many participants chose to write about more than one topic during each session.

\section{Content Analyses of Writing}

Comparisons were conducted on the writing products created by the emotional and nonemotional writing groups. There were no group differences in word count overall, or on any of 
the three writing days, maximum $\mathrm{E}(1,35)=1.17, \mathrm{p}>.05$. Across all sessions, participants in both groups averaged 342 words per essay.

The writing products written by participants in the emotional and non-emotional groups were analyzed using Pennebaker's LIWC package described earlier. The overarching standard categories included: standard linguistic dimensions, psychological processes, personal concerns. relativity, experimental dimensions, and physical dimensions.

The LIWC content analysis was sub-dividedon include the following categories: linguistic dimensions, emotional expression, cognitive strategies, content dimensions, and physical dimensions. Each category included items related to and representative of their respective category (e.g. anxiety, anger, and sadness were included within the emotional expression category). Each item was summed across all three writing sessions and then averaged. Table 4 provides an overview of the results of one-way analyses of variance (ANOVAs) performed for each item. Due to the fact that the categorical dimensions were intercorrelated. group differences for each category were tested using a multivariate analysis of variance (MANOVA) using Wilk's lambda. In such analyses, writing condition (emotional vs. non-emotional) was the independent variable and the variables comprising the categories listed above were the dependent variables. There were highly significant differences between the emotional and non-emotional writing groups in terms of emotional expression (e.g. anger, anxiety, affect, negative emotionality, sadness and feeling, etc.), $\mathbf{F}(8,28)=16.56, \underline{\mathrm{g}}<.001$, cognitive strategies (e.g. insight, causation, and cognition), $\mathrm{F}(5,31)=23.14, \mathrm{Q}<.001$, content dimensions (e.g. school, home, and death, etc.), $\underline{F}(7,29)=8.20, \underline{\mathrm{g}}<.001$, linguistic dimensions (e.g. references to we, other, and self), $\underline{F}(4$, $32)=12.29, \mathrm{p}<.001$, and physical dimensions, $\underline{\mathrm{F}}(2,34)=18.15$, 
Table 4

LIWC Analysis of Writing Products

Variables Measured

\section{Emotional Non-emotional$$
\text { writing }
$$

$\left(N_{1}=18\right) \quad\left(N_{2}=19\right)$

M

Standard Writing

Word Count

373.29

M

Linguistic Dimensions

You

We

Other

Self

Emotional Expression

Anger
Anxiety
Affect
Negative Emotionality
Sadness
Positive Feelings
Optimism
Feeling

Cognitive mechanisms
Insight
Causation
Tentativeness
Certainty

Content Dimensions

School

Home

Death

Occupation

Sports

Leisure Time

Social Matters

Metaphysical

$\begin{array}{rr}1.36 & .28 \\ .60 & .14 \\ 6.11 & 2.93 \\ 3.57 & .53 \\ .94 & .10 \\ 1.08 & .26 \\ .93 & .10 \\ 1.06 & .24\end{array}$

1.03

.78

.19

1.85

.40

1.58

12.03

.24

1.08
1.97

1.50

.007

3.04

1.47

3.72

9.42

.09
.23

3.04

1.43

13.89

.28

2.93

.53

10

26

.24 $\left(1, \frac{F}{34)}\right.$

1.07

$p>.05$ p

\section{\begin{tabular}{lrr} 
Cognitive Strategies & & \\
\hline Cognitive mechanisms & 6.99 & 2.91 \\
Insight & 2.11 & .78 \\
Causation & 1.38 & .40 \\
Tentativeness & 2.42 & 1.08 \\
Certainty & 1.31 & .62
\end{tabular} \\ \begin{tabular}{lrr} 
Cognitive Strategies & & \\
\hline Cognitive mechanisms & 6.99 & 2.91 \\
Insight & 2.11 & .78 \\
Causation & 1.38 & .40 \\
Tentativeness & 2.42 & 1.08 \\
Certainty & 1.31 & .62
\end{tabular} \\ \begin{tabular}{lrr} 
Cognitive Strategies & & \\
\hline Cognitive mechanisms & 6.99 & 2.91 \\
Insight & 2.11 & .78 \\
Causation & 1.38 & .40 \\
Tentativeness & 2.42 & 1.08 \\
Certainty & 1.31 & .62
\end{tabular} \\ \begin{tabular}{lrr} 
Cognitive Strategies & & \\
\hline Cognitive mechanisms & 6.99 & 2.91 \\
Insight & 2.11 & .78 \\
Causation & 1.38 & .40 \\
Tentativeness & 2.42 & 1.08 \\
Certainty & 1.31 & .62
\end{tabular} \\ \begin{tabular}{lrr} 
Cognitive Strategies & & \\
\hline Cognitive mechanisms & 6.99 & 2.91 \\
Insight & 2.11 & .78 \\
Causation & 1.38 & .40 \\
Tentativeness & 2.42 & 1.08 \\
Certainty & 1.31 & .62
\end{tabular} \\ \begin{tabular}{lrr} 
Cognitive Strategies & & \\
\hline Cognitive mechanisms & 6.99 & 2.91 \\
Insight & 2.11 & .78 \\
Causation & 1.38 & .40 \\
Tentativeness & 2.42 & 1.08 \\
Certainty & 1.31 & .62
\end{tabular} \\ \begin{tabular}{llr} 
Cognitive Strategies & & \\
\hline Cognitive mechanisms & 6.99 & 2.91 \\
Insight & 2.11 & .78 \\
Causation & 1.38 & .40 \\
Tentativeness & 2.42 & 1.08 \\
Certainty & 1.31 & .62
\end{tabular} \\ \begin{tabular}{llr} 
Cognitive Strategies & & \\
\hline Cognitive mechanisms & 6.99 & 2.91 \\
Insight & 2.11 & .78 \\
Causation & 1.38 & .40 \\
Tentativeness & 2.42 & 1.08 \\
Certainty & 1.31 & .62
\end{tabular} \\ \begin{tabular}{llr} 
Cognitive Strategies & & \\
\hline Cognitive mechanisms & 6.99 & 2.91 \\
Insight & 2.11 & .78 \\
Causation & 1.38 & .40 \\
Tentativeness & 2.42 & 1.08 \\
Certainty & 1.31 & .62
\end{tabular} \\ \begin{tabular}{llr} 
Cognitive Strategies & & \\
\hline Cognitive mechanisms & 6.99 & 2.91 \\
Insight & 2.11 & .78 \\
Causation & 1.38 & .40 \\
Tentativeness & 2.42 & 1.08 \\
Certainty & 1.31 & .62
\end{tabular}}

$21.30 \quad \mathrm{p}<.001$

$12.81 \quad \mathrm{p}<.001$

$46.96 \quad p<.001$

$96.84 \quad p<.001$

$40.99 \quad \mathrm{p}<.001$

$52.38 \quad \mathrm{p}<.001$

$40.99 \quad \mathrm{p}<.001$

22.14

$\mathrm{P}<.001$

Phvsical Dimensions

Physical States/Functions

59.39

36.63

34.36

30.04

17.10

5.70

11.27

17.59

6.92

12.36

24.28

6.51

20.10

22.02

$$
\begin{aligned}
& p<.001 \\
& p<.001 \\
& p<.001 \\
& p<.001 \\
& p<.001
\end{aligned}
$$

$$
\begin{aligned}
& p<.05 \\
& p<.001 \\
& p<.001 \\
& p<.05 \\
& p<.001 \\
& p<.001 \\
& p<.05 \\
& p<.001
\end{aligned}
$$
.57
Symptoms and Sensations
.06 
Emotional Disclosure and Health 46 $\mathrm{p}<.001$. As predicted, the analysis revealed that the emotional writing group ranked much higher on these categorical variables compared to the non-emotional writing group. While these results are consistent with previous research conducted on adults on the analysis of emotional disclosure writing session, some distinctions were worth mentioning. The emotional writing group showed a higher frequency of positive affect and optimism, and a lower frequency of references to physical states and functions and home life, as compared to those in the non-emotional writing condition.

\section{Psvchological Changes After Writing}

After each of the three writing sessions, participants in both the emotional and nonemotional writing groups were asked to rate the degree to which they were feeling each of eight emotions at the moment. Mean values for each emotion were calculated by averaging scores across writing days. A summary of these values can be observed in Table 5. The resulting mean averages were then subjected to a $2 \times 2$ (writing condition $\times$ pre. vs. post writing) mixed factorial ANOVA. There was a significant main effect for time (pre vs post writing), in terms of nervousness, $\mathrm{F}(1,34)=7.12, \mathfrak{p}<.001$, wherein both groups decreased over time. Significant interactions were found for excitement. $\underline{F}(1.34)=6.74 . \mathrm{g}<.01$. upset. $\mathrm{F}(1.34)=5.00, \mathrm{p}<.01$, and shame, $\underline{F}(1,34)=5.61, \underline{p}<.01$. These interactions are depicted in Figures 3, 4, and 5. The non-emotional writing group increased significantly pre-post writing session in terms of excitement when compared to the emotional writing group. With respect to shame however, the emotional writing group showed a significant increase pre-post writing session compared to the non-emotional writing condition. In terms of upset, the emotional writing group showed a significant increase pre-post writing compared to the non-emotional group. 


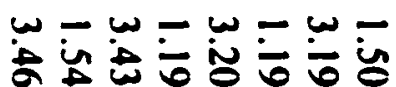

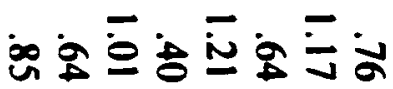

13

ק

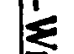

登

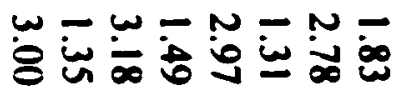

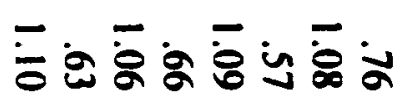

K

登:

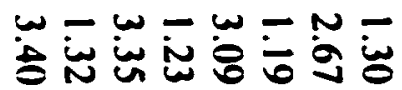

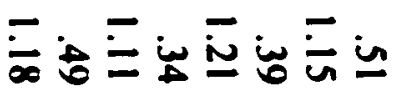

13

售

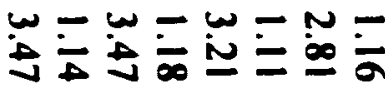

$\mathbb{B}$

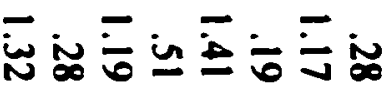

E

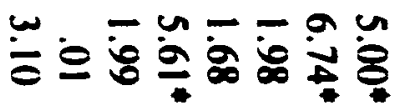
$n$

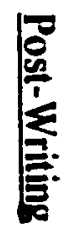

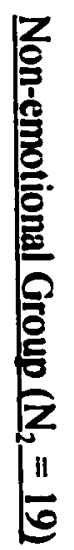




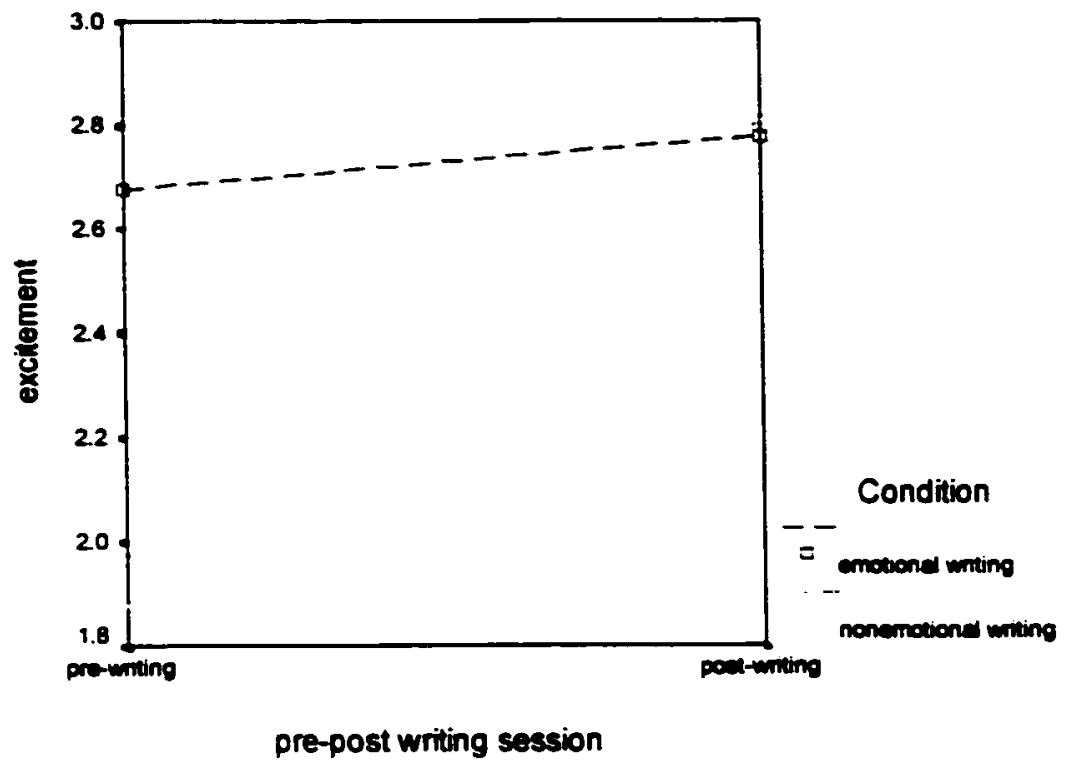

Fipure 3. Mean excitement score as a function of writing condition and time (pre-post writing session).

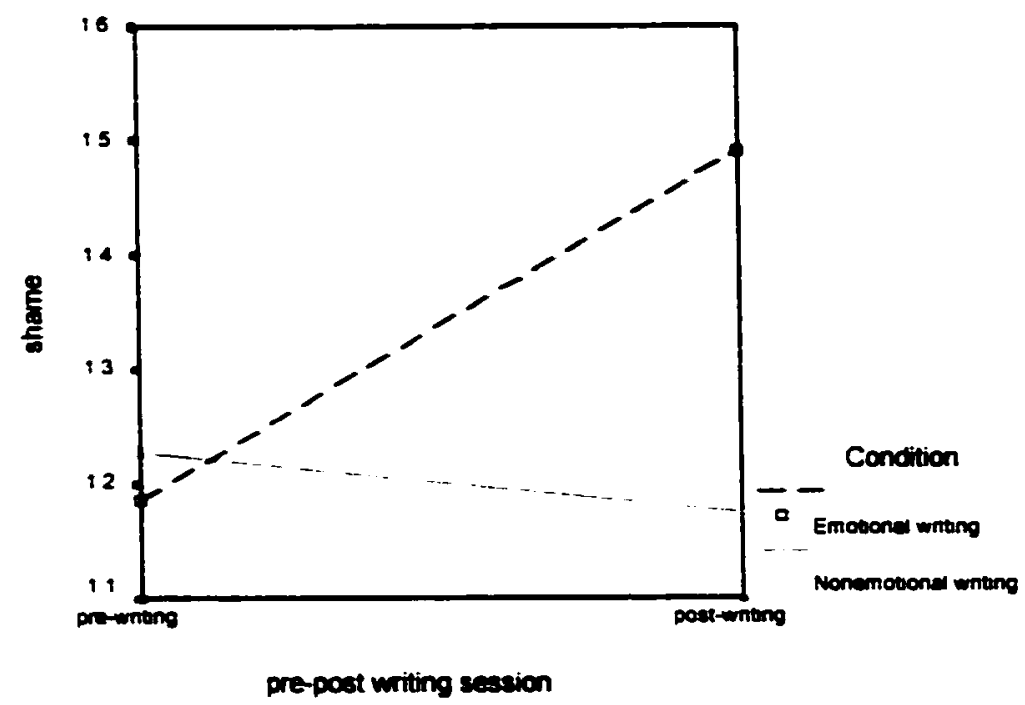

Fiqure 4. Mean shame score as a function of writing condition and time (pre-post writing session). 


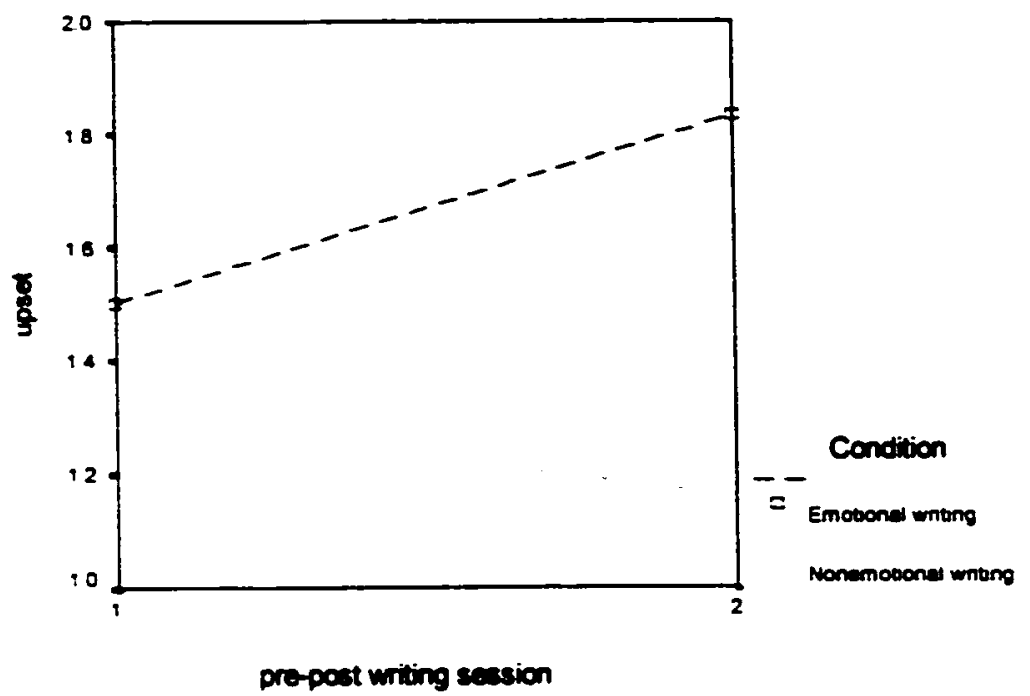

Fiqure 5. Mean upset score as a function of writing condition and time (pre-post writing session) 
Emotional Disclosure and Health 50

\section{Effects of the Interventions}

In order to assess the impact of the writing intervention a series of $3 \times 2$ (group $\times$ time) mixed ANOVA's were performed for each of the dependent measures. There were no significant effects of group, nor were there any interactions of group by time. Results did show however. significant main effects for time across all groups on internalizing symptoms, $\underline{F}(1,50)=12.36, \underline{p}<$ $.001]$ and physical symptoms, $\underline{F}(1,50)=5.19, \mathrm{p}<.01$. Across all groups there was a significant decrease in both internalizing and physical symptoms. While there were no significant changes over time on the SDQ measure as a whole, significant differences were found with respect to the prosocial, $\underline{F}(1,52)=4.23, \mathrm{p}<.01$, and conduct problem, $\underline{E}(1,52)=14.36, \mathrm{p}<.01$, subscales. There was a significant increase in prosocial behavior and a significant decrease in conduct problems for all groups. There were no significant changes over time on the Positive and Negative Affect measure as a whole. Subsequent repeated measures analyses for both the positive and negative affect subscales of this measure, however, did reveal a significant main effect for time on negative affect, $\mathrm{E}(1,52)=4.67, \mathrm{p}<.01$. In general, there was a significant decrease in negative affect over time for all groups. Again. there was no group by time interaction. What the results indicate is that all groups improved over time, but that no one group improved significantly over the other. Thus, emotional disclosure failed to convey any additional benefits.

Further analyses were carried out to examine whether certain subsets of the population may have evidenced beneficial effects. A series of $2 \times 2$ (gender $\times$ time), mixed factorial ANOVA's were performed for each of the dependent variables in order to test for significant effects of time by gender. Results showed a significant gender $\times$ time interaction for physical symptoms. $\underline{F}(1,51)=4.91, \underline{p}<.01$ (Refer to Figure 5 for an illustration of this finding). 
Emotional Disclosure and Health 51

Inspection of these results showed that males decreased significantly over time on physical symptoms $\left[\underline{M}_{n}=1.90\right.$ to $\left.\underline{M}_{c}=1.61\right]$, while females remained the same $\left[\underline{M}_{11}=1.97\right.$ to $\underline{M}_{c}=$ 1.97]. No other significant gender differences on any of the remaining dependent measures were found.

A series of $2 \times 2$ (age category $\times$ time) mixed factorial ANOVA's, were performed to test for any significant effects over time by age category. The results suggested a significant interaction of age category by time for positive affect, $\underline{F}(2,50)=4.65, \underline{p}<.01$. As seen in Figure 7, these effects reflect the fact that scores on overall affect were not the same for each age category over time. It was apparent the older participants decreased in positive affect. while younger participants increased in positive affect. Significant main effects of time were found for internalizing symptoms, $\underline{\mathrm{F}}(1,50)=12.36, \mathrm{p}<.001$, and physical symptoms, $\underline{\mathrm{F}}(1,50)=5.19 . \mathrm{D}<$ .01 . With respect to these variables, significant decreases over time were noted. 


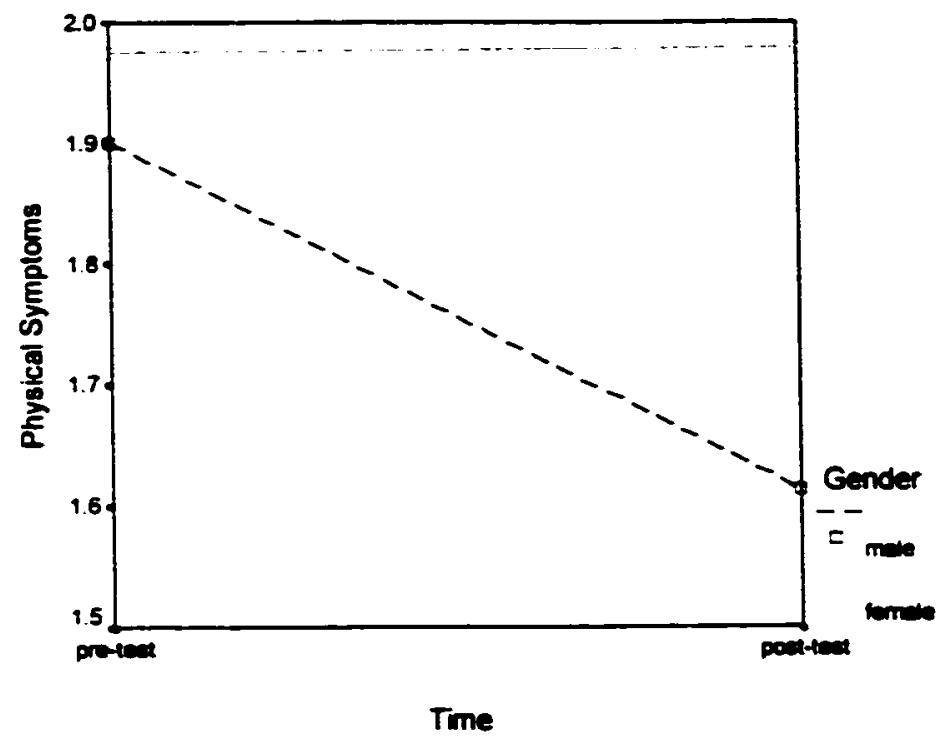

Figure 6: Mean physical symptoms score as a function of gender and time.

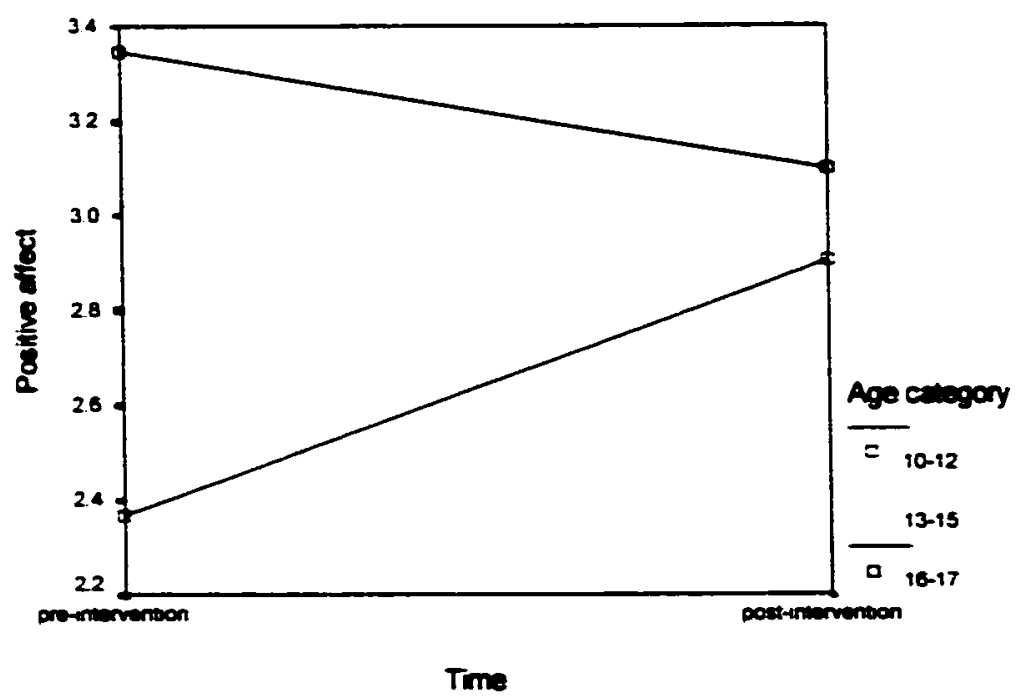

Fipure7. Mean positive affect score as a function of age category and time. 


\section{Chapter V}

\section{Discussion}

The present study, while effective in design and execution, failed to produce results in the predicted direction. The main hypothesis, that the participants in the emotional writing group would evidence the greatest improvement over time, was not supported. The results did not substantiate the predicted interaction of time by intervention group, whereby the emotional writing group should have selectively evidenced the greatest improvements in physical and psychological functioning over time. Contrary to what was hypothesized, a general improvement in selective areas of physical and psychological functioning was seen across all groups.

The second hypothesis, that participants in the emotional writing group would show gradual cognitive assimilation and understanding of the events they wrote about. was substantiated. Essentially, it was observed that participants in the emotional writing group made use of more cognitive, insight and causal related words. This observation held up over time. The fact that the emotional group essays contained a significantly higher proportion of cognitive mechanism words does indicate that cognitive processing was occurring. Across time, however, these participants did not increase significantly in the number of cognitive words they used. This is to say that the essays did not contain a significantly higher proportion of cognitive words on the third day of writing compared to the first day of writing. What this could suggest is that participants were not given enough writing space or time (i.e. 5 days of writing) to facilitate greater cognitive processing. It has been noted (Smyth, 1998) that stronger and more pronounced effects have manifested in those studies which employed a greater number of writing sessions. The results stemming from this hypothesis could also have been limited by the program used to 
Emotional Disclosure and Health 54 analyze the text itself. It could be that the Linguistic Inquiry and Word Count Program, created and tested on college samples, was limited in its ability to draw links between a young persons writing and their emotional and cognitive worlds. It could be that the words used by adults which indicate physical and psychological functioning differ from the categorical words used by young people to indicate physical and psychological functioning.

The third hypothesis, that those who rated the events they chose to write about as more severe would show greater overall improvement, was not substantiated. There was a significant interaction of severity by time; however, contrary to what was predicted, the non-emotional writing group showed an increase in positive affect over time. while the emotional writing group decreased in positive affect. One probable explanation for this is that the follow-up period of one month was too short in duration. A recent study by Greenberg and Stone (1992) found significant differences between severe and non-severe writing groups. but these occurred two-months after the experimental writing paradigm had been completed. This suggests that the effects of emotional writing on affective functioning may need a minimum period of time to manifest and that the present study failed to provide sufficient time. A combination of multiple follow-ups (e.g. one each month for four months after the writing exercise) could have helped to assess whether the time between the writing intervention and follow-up influences physical and psychological functioning.

An exploratory examination of gender revealed that males in the group decreased on physical symptoms while females remained the same. This was a surprising finding in light of the fact that females have been noted to report a higher level of physical symptoms compared to males and they engage in self-monitoring more often (Harnish \& Sullivan, 1987). However, in the 
Emotional Disclosure and Health 55

middle school years it has been noted that boys tend to engage in self-monitoring more than girls for popularity purposes (Musser \& Browne, 1991). Thus, it could be that the male participants in this study were monitoring their physical effects more closely than were the female participants. It is also interesting to note that in a meta-analysis of extant emotional disclosure studies, Smyth (1998) commented that males were more likely to evidence health improvements as a result of writing compared to females.

An additional exploration of age differences uncovered a significant interaction of age by time. These results indicated that individuals in the youngest age category (10-12), showed an increase in overall affect over time. while those in the two higher age categories (12-15 and 1617), showed a decrease in affect over time. Subsequent examination of these results in terms of the positive and negative affect sub-scales revealed that there was an increase in positive affect over time for the youngest age category, while the two older age categories actually decreased in positive affect. This is an interesting finding worthy of further investigation. It has been noted that among young, middle and older aged adults, there are few significant differences in levels of positive affect (Lawton. Kleban, \& Dean. 1993). In a study conducted across the lifespan, it was observed that an increase in age was accompanied by an increase in emotional stability and a leveling of positive affect (Lawton, Kleban. Rajagopal. \& Dean. 1992). While this may help to explain the age related effects in this study, an absence of literature on age related differences in positive affect during the middle and adolescent years precludes any conclusions with respect to the significant finding.

It is also possible that the age related differences for positive affect observed in this study are due to differences in emotional development. It has been noted that middle childhood and 
Emotional Disclosure and Health 56

adolescence are two separate emotional development periods each marked by different stages and levels of functioning (Feldman, 1998). With respect to affective development. it has been reported that during adolescence negative emotion becomes more readily incorporated into one 's identity (Haviland, Davidson. Ruetsch, Gebelt, Janet, et al., 1994). This could help to explain why the older aged participants decreased in positive affect over the course of the study.

What was most apparent from the results was an overall reduction in both physical and psychological symptoms across the entire sample. This was especially evident with respect to negative affect, internalizing symptoms, and physical symptoms. There were also significant and notable effects for the pro-social behavior and conduct problems subscales of the SDQ measure. These findings are inconsistent with findings from some other emotional disclosure and health. which have noted an overall improvement in physical and psychological functioning for those who write about deeply personal events compared to those who do not (Smyth. 1998).

The results found in the present study are not unparalleled. In fact, studies do exist which have failed to show beneficial health effects as a result of emotional disclosure in the form of writing (Kloss. 1998) With respect to the recognized emotional disclosure studies involving children. the results have been contrary to what was hypothesized in the current study. In one of the first studies to examine emotional disclosure in children. Springer and Penenbaker (1995) failed to find any significant effects of writing condition by time. In this specific study, the only marginally significant results were a few weak correlations between variables identified through a content analysis of the writing products. In addition. a second, and more recent study, by Reynolds et al. (2000). failed to find significant effects for writing condition. In fact. this study also found a general improvement in functioning across all groups. 
Emotional Disclosure and Health 57

Compared to the execution and findings of previous studies on emotional disclosure with children, the present study did differ in some notable ways. First, this study involved children of alcoholics, a population known to have a history of stressful experiences. This could explain why the experimental manipulation was successful, in that participants in the emotional writing group actually wrote about stressful events while those in the non-emotional group wrote about superficial events. It has been suggested that children of alcoholics are a group known to repress their emotions and are thus. unlikely to naturally divulge personal thoughts and feelings (McNamee \& Offord. 1994). In this study, the experimental manipulation did appear successful in being able to facilitate emotional expression in children of alcoholics. This was evidenced by the fact that the emotional writing group wrote in depth and at length about their thoughts and feelings with respect to personally stressful events. In previous studies, it was found that the writing instructions were not followed as some of the emotional writing group participants wrote about non-emotional events while some of the non-emotional writing participants wrote about stressfiul events (Reynolds, et al., 2000).

The Reynolds et al.. study (2000), also facilitated the writing experiment by having participants write in groups. The present study had participants write in isolation, thus assuring them privacy. Another notable difference was the fact that in this study the non-writing control group was not given any form of intervention and the concept of stress was not discussed. In the Reynolds et al. study, the non-writing control group was exposed to a three day discussion about the diary writing. This practice may have indirectly influenced the results of their study. The last major difference was the amount of time between pre and post test measurement. This study involved a one month follow-up assessment, whereas the previous study carried out a two month 
post-intervention follow-up assessment. While the present study did manage to differ in experimental design from the Reynolds et al. (2000) study, the results were highly similar. This suggests that the emotional disclosure writing task, designed and implemented by Pennebaker (1989), may have limited utility with younger populations.

There could be a number of separate and independent reasons for the observed results of the present and aforementioned studies. One of the most feasible reasons is that participants of this age group may lack the intellectual maturity to accurately express themselves in words (Springer, personal communication. November 9, 2000). They may have yet to master the grammatical and structural components required for English writing composition. As a result, it may have been difficult for them to write expressively. According to existing research, the writing paradigm is dependent upon the ability to form an organized and coherent account of a stressful event. identify the thoughts and feelings associated with the event. and translate the event and its accompanving thoughts and feelings into language (Pennebaker, Mayne, \& Francis. 1997). It could be that the cognitive and linguistic abilities required for the writing paradigm are not fully functional for the ages examined in this study.

With respect to the present study, it was observed that many of the participants found it difficult to write at length. especially about the same topic. In fact, many of the essays contained multiple themes and participants tended to move from subject to subject quite abruptly. This is contrary to emotional disclosure studies involving adults. where it has been reported that experimental subjects "readily disclose deeply personal and emotional topics." (Pennebaker, 1997a p. 539). This could suggest that with the age range involved in this study, the ability to express oneself through writing is not usually fully developed or functional. It has been noted that 
Emotional Disclosure and Health 59

both preteens and early adolescents lack both oral and written linguistic sophistication (Feldman. 1998). This deficit requires time and refinement to reach adult levels of linguistic expression.

With respect to linguistics, there is often a lack of metalinguistic awareness among individuals of this age group. Metalinguistic awareness refers to the ability to understand one's own use of language (Kemper \& Vernooy, 1994). Such awareness enables people to comprehend their thoughts and experiences when information is unclear or ambiguous. In the present study, participants were asked to write about stressful events. There was no indication. however. if the participants were able to understand these events. On observation of the writing content, it was apparent that participants had difficulty writing at length about their stressful experiences. This could be considered evidence that there was a lack of comprehension. Alternatively, it could be evidence that participants were unable to translate their experiences into language.

The observation of a lack of comprehension among participants could also be explained by the Sapir-Whorf hypothesis. According to this hypothesis. cognition is dependent on language (Wolfson. 1973). This hypothesis implies that language dictates human thought. With respect to this study, it could be possible that young people have yet to acquire the specific language tools necessary to enable them to think about events which have been stressful or traumatic. This could explain why participants in the emotional writing condition were able to describe the stressful or traumatic event, but were unable to write at length about it.

In addition. participants of this age group may not be used to, or very adept at, exploring their inner selves. According to Feldman (1998), both the middle childhood and adolescent years are marked by an attempt to explore and understand the nature of the self. While individuals in these years begin to view themselves in terms of psychological characteristics, it is uncertain as to 
Emotional Disclosure and Health 60 whether they are able to fully comprehend or communicate who they are externally. Thus. having them write about their inner selves may be a new experience which requires time to develop.

The fact that the target population for this study was under the age of consent added additional constraints not present in studies on emotional disclosure in adults. The first of these constraints was the fact that participants had to be instructed to write in general about stressful experiences. As a result, they may not have focused on those experiences which have been traumatic or deeply painful for them. In many studies on emotional disclosure involving adults. the instructions have specifically directed participants to "...write about the most upsetting emotional experience of your entire life" (Dienstfrey, 1999, p. 161). Consequently, the essays predicated upon these instructions have proven to contain content of a deeply personal and troubling nature. The fact that the present study precluded such instructions could bave limited the extent to which participants engaged in full emotional disclosure. As a result. the noted benefits of emotional disclosure could have been minimized.

Another issue related to experimental studies with underage populations is that of confidentiality. Participants were made aware that their writing would remain confidential unless there was evidence of self-harm. In the case of self-harm, participants were told that their parents would be contacted. This in and of itself could have precluded participants from full disclosure. Throughout the study, there was evidence that participants were concerned about confidentiality. For example. on a number of occasions. the investigator was asked by participants whether or not their parents would be reading the contents of their writing. It has been suggested elsewhere, that even when young people are assured confidentiality, they still tend to believe that their parents will receive this confidemtial information (Abramovitch, Freedman, Thoden, \& Nikolich, 1991). 
Emotional Disclosure and Health 61

The overarching observation from this study is that all groups showed a general improvement with respect to physical symptoms, internalizing symptoms, and affect. The observed results could be considered in light of a possible Hawthome effect. In this respect. the general improvement seen in all groups could have been due to effects other than those of the manipulation of the independent variable. This could include the experimenter paying attention to each participant.

Another possible explanation for the observed results is that participants may have benefitted from an incentive. In this study, participants were assured a reward after their successful completion in the study. Being involved in a structured activity may have influenced well-being positively. Another possible explanation is that participants may have benefitted from the mere act of participation. This is to say that being involved in a structured activity may have influenced well-being positively. This is consistent with the study on emotional disclosure with school children conducted by Reynolds. et al., (2000), which also suggested that the act of involving young people in stress-related interventions may in and of itself, promote well-being.

\section{Essay Content}

It is difficult to impart the depth of context which arose from the personal essays of those in the emotional writing group. In order to provide a better understanding of this depth however, a small number of writing examples which illustrate the types of things participants found stressful as well the nature of expression with regard to these stressful events has been provided. While these examples do not characterize the majority, for each essay was unique, they do convey a flavor for the writing style and content.

A significant proportion of essay content was devoted to family issues. A sample of such 
content is evidenced in the following examples:

"Usually on Fathers day I am really upset and cry all day, I really don't know why. My. aunt made a comment to my mom saying that maybe it was because I don't know my real dad. The guy I called Dad was a drunk which was my sisters dad. He totally fovored my sister over me. She'd always get more things than me". (15 year old female)

"This problem has been going on for I think 8 weeks. It's how my family is smaller. because my dad has left and put himself in a big depth, and left my mom a weak and helpless and disabled and the house a wreck I think he's gonna stop paying the bills and the money to use and we will have to file for bantruptcy and they will take all the stuff and we will be left on the streets with nothing and nowhere to go that's one of $m y$ big fears of all. And I can't help but feel like my dad doesn't love us like he hardly ever calls to talk to me or my brother I know now my dad knows nothing about me because he was always drunk after work and all he did everywhere was drink beer and smoke and sometimes watch football or hockey. And I know he doesn't know me because he bought me a camera for Christmas last year a throw away one. I'm still not done the film for it". (16 year old male)

"Once I was very mad at my mom and I really wanted to call her a bitch but I didn't! She sent me to my room and when she left I called her a bitch and she heard but didn't say. anything to me. I probably hurt her feelings by calling her a bitch. Then the next day she told my stepdad that I called her $a$ bitch and he asked me why and I said I don't know and he said why don't you know and I said I don't know! I felt ashamed of myself when I called my own mother a bitch! I was very said when I did that but I thought about it for awhile and I finally got my answer". (10 year old female)

Peer Problems were another common theme for the emotional writing group participants:

"This year my best friend started smoking because now she's in highschool. Her new highschool friends smoke so I tried to avoid her. and I got a new best friend. My new best friend met my old one and they became really good friends. Now my new best friend smokes! It's kind of confusing I was surprised and mad. I couldn't believe she did that. At first it was just cigarettes but later it turned into drugs. I don't like being around people who smoke. I don't know what to do because I can't just dump my new friend". (II year old female)

Another common theme was bullying and fighting at school:

"He pushed me into the wall. I told the teacher instead of fighting back. That kid gets on my nerves man. Oh ya, often is this kid named .... he always killed me. He kicks me in the shoulder and it drove my head into the wall". (10 year old male) 
Other essays clearly showed the amount of stress accompanied by a personal event:

"When I was in grade 10, I was bullied and picked on about an untrue rumor. I was harassed and felt along. Everything my pride, personality, enthusiasm, and most of all what I came very close to losing, my love for school. I challenged God, I felt helpless and angry.I struggled with each day, and no one knew. I pushed down all of my feelings and put on a smile. I thought that no one would tell how much I was hurting and then they would drop it. However, that didn't happen., I continued to feel left out and alone". (17 year old male)

Overall, the content of the essays ranged in severity. An example of this range can be observed in the following quotes:

"There was a time when I really felt sad when my friend Cody Sands moved to another home far away from here". (12 year old male)

"I get bored alot because I don't have anything to do in my house".(10 year old female)

"I have a lot of thoughts and feelings I have kept inside of me. My mom and dad broke up after I was 4 , they weren't married, and they didn't divorce". (12 year old female)

-A long time ago it mad me feel so bad $i$ was ready to kill myself. $i$ had the knife and was ready to do it..." (16 year old male)

Some of the scripts clearly showed emotional processing and a sense of resolution to the stressing problem:

"I guess a big topic about this issue is my self-esteem. Right down to it I don't have a big self-esteem. I think it's because I have always got teased since fth grade. One reason is that I'm very emotional with my feelings. If the teasing is about my looks. or if it just about myself going to church. I get teased. But in the past year I have learned to build up my self-esteem. so that's a positive. I have started to play drums and have found something I am good at so. I'm happy about that". (13 year old male)

While many essays did reveal a great depth of emotion, some of the essays showed an attempt on the part of the participant to not want to write at length about personally troubling experiences. In fact, in both conversation and penmanship, there was an indication that participants in the emotional writing group would rather write about positive experiences. 
"In grade five I got reased quite a bit. And again I didn't know how to handle it. One of the reasons I started to cry and was really, really embarassed about it. I'm sorry I can't write about it. If I even start to think about it. I become sadder than I need to be. I rather talk about happy things and not sad things". (14 year old male)

In addition. some essays expressed contradictory emotions:

"Something in my life that made me really sad was when I found out my mom had cancer. It is hard for me because it made me feel and cry a lot and it makes me get mad a lot at other people. It was three and a half years ago when I started to do this. I still think about it the same all the time. I cry about it often about 2 times $a$ week and I cry by myself. I haven't cried about it in front of anyone because everybody had known their moms longer than me. I can talk about it with somebody. In a couple of days maybe I'll talk about it. I'm usually happy everyday. I don't think it is fair and I don't like it at all". (10 year old female)

A number of essays contained a number of distinct and non-overlapping topics and the transitions from one topic to another were often made quite abruptly.

"But the girl that threw the rock at my head got grounded for two weeks. But the thing that is the worst is when my dad died. There is one more that thing I can say is that girls make fun of me and they swear at me words like fuck you bitch. I can't think of anything right know so that's all I have to say about that goodbye for now". (10 year old male)

Overall, the qualitative content produced by participants in this study showed that participants did indeed have personally stressful events to write about. Moreover, it was clear that these events had evoked strong thoughts and feelings which were able to be communicated through written language. Analyses conducted with the LIWC program showed significant differences between the emotional and non-emotional groups in terms of emotion and cognition. Thus, the study was successful in being able to get young people thinking about personally troubling experiences. The overall results, however, suggested that for this population, it may not be sufficient to simply engage in written emotional disclosure since simply writing about what has been stressful or traumatic failed to significantly influence health and well-being in the long run. 
Emotional Disclosure and Health 65

\section{Limitations}

A discussion of the results of the present study would not be complete without mentioning its limitations. One of these was the reliance on self-report measures. In many of the extant studies involving emotional disclosure there have been a mixture of both objective and subjective measures, of which objective measures have shown the most significant effects (Smyth. 1998). In fact. writing about emotional upsets has been noted to have little effect on psychological functioning when measured subjectively (Pennebaker, Zech, \& Rime, in press). Due to financial constraints, the present study failed to include any objective measures. Examples of such objective measures include blood samples, immunoassay tests, and blood pressure monitoring. All of these measures are designed to subtle minute and specific physical changes and have proved vital in the detection of physical changes in many emotional disclosure studies (Smyth, 1998). It is possible that the use of such measures in the present study could have enabled detection of significant changes in physical functioning not evident through physical symptom self-report measures.

In addition. the present study did not make use of either parental or teacher reports on child symptoms and behavior. It could be that a behavior change did occur in participants' which they could not self-identify. Athough this is possible, a recent study by Reynolds et al., (2000), which made use of both parent and teacher behavioral rating scales, did not find significant differences between experimental groups over time as a result of the emotional disclosure intervention. This study, however, only used parent and teacher ratings for one measure (SDQ) thus. it is uncertain whether the results might have differed if ratings were taken on the remaining dependent measures.

The present study was also limited by a small sample size $(\mathrm{N}=53$ ). It could be that a 
Emotional Disclosure and Health 66

larger sample would have shown results in the hypothesized direction. Of the studies already conducted on youth, however, large sample sizes did not influence the results (Reynolds et al., 2000). In fact, the Reynolds et al. study, with a sample size of 191, failed to produce a time by intervention group effect. In addition, a power analysis performed ad-hoc, concluded that a minimum of ten subjects per group was sufficient based on the overall effect size for extant emotional disclosure studies. The present study exceeded this minimum value.

The fact that the writing exercise took place over three consecutive days might have also influenced the results. More specifically, fatigue from having to write for 20 minutes on each day could have limited the extent to which the intervention had a positive effect. It was apparent that with each successive day, there was a decrease in word count. This was true for both the emotional and non-emotional writing groups. There was the additional observance that on the third day, many participants found it difficult to sit down to write. By the third day. some participants also verbalized that they were "running out of things to write about".

The timing of the study could also have influenced the pattern of responding observed. The study began in late November and ended in early February. As a result. the majority of pretesting was done before Christmas while the majority of post-testing was done immediately after Christmas. It could be that the Christmas holidays, complemented with a festive atmosphere and time off school, could have buffered both physical and psychological stress, thereby promoting an improvement in overall well-being. This could help to explain why there was a significant improvement for all groups on many of the dependent measures.

It has been suggested that the health benefits accrued by the writing paradigm take time to manifest (Pennebaker. 1997a). In the present study, follow-up measures were take one month 
Emotional Disclosure and Health 67

after writing. It is possible that a one month post-writing period was not adequate. This could account for why a significant improvement in functioning was not seen in the emotional writing group. In a majority of the extant writing paradigm studies conducted to date. the minimum postwriting period has been one month (Smyth, 1998). In fact, the general conclusion based on these studies is that significant differences between experimental and control groups tend to be most eminent a few months after writing (Pennebaker, 1993). Due to the age and nature of the population of this study, it could be that a prolonged post-writing period is required in order for a full effect to become observable.

Another possible limitation could be the fact that most of the participants were the children of recovering alcoholics. In effect, it could be that children of recovering alcoholics differ from children of practicing alcoholics. As a result, emotional writing may not have afforded them the benefits it would a child of practicing alcoholics. While the suggests that children of recovering alcoholics often go without intervention, and are equal in need to those children of practicing alcoholics, lack of systematic research comparing these two groups prevents any conclusion as to whether and how these two groups differ literature(McNamee \& Offord. 1994). Thus. it is possible that the results of this study may have come out differently if participants were the offspring of alcoholic parent(s) who had never received help or who were still practicing.

\section{Recommendations}

It is important in to distinguish between emotional disclosure as an intervention versus a reflection of stress. It could be said that asking participants about their thoughts and feelings during three consecutive and brief encounters only facilitates a brief reflection of stressful events rather than a full exploration of these events. In this sense, an intervention would ensure that 
Emotional Disclosure and Health 68

active confrontation, processing, and resolution of a stressful event was accomplished.

What the results of this, and other existing studies suggest, is that pilot programs exploring different emotional disclosure interventions with younger populations could produce the positive effects seen in studies on emotional disclosure with adult populations. This could involve the use of dictaphones, whereby participants could engage in verbal emotional disclosure over a longer period of time (eg. two month periods). Additionally, the use of a computer generated program which could allow children to speak into a microphone and have their thoughts and feelings automatically transcribed directly onto paper is another possibility.

Another suggestion for future study would be to include the use of neutral writing probes. For example, music has been used as a therapeutic tool with children to help them identify and project their thoughts and feelings (Clendenon-Wallen, 1991). Another suggestion would be to have structured cue cards from which the examiner could provide writers with ideas of what to write about. In the present study, it was difficult for participants to begin writing due to lack of ideas. It would be interesting to see whether or not giving them vocal idea probes prior to the onset of writing would facilitate more in-depth writing.

Future studies could also benefit from an examination of child coping mechanisms. Middle school-aged and young adolescents are a unique population and have been noted to employ different strategies in their attempt to deal with stress (Folkman \& Lazarus. 1988). It could be that the individuals in the present study had already managed to cope with the stress they had experienced. On the other hand, it could also mean that these individuals were engaging in repressive coping mechanisms. It is also uncertain as to whether or not individuals were already positively influenced by other supportive connections (e.g. social support, school interventions). 
Emotional Disclosure and Health 69 A systematic assessment of these factors could help to understand the results of the present study. It has been stated that translating personally stressful or traumatic events into words is a fundamental human task (Pennebaker, 1997b). Such an observation has led to the investigation of how writing about events of a psychological nature can influence mental and physical health. While emotional disclosure interventions with adult populations have been encouraging. the effects have not been as significant for younger populations. It is too early to objectively comment on the reasons for these different age related effects; however, current research investigating the basic mechanisms of the emotional disclosure phenomenon are hoped to aid in an understanding. As of now. it does seem evident that younger populations are not afforded the beneficial consequences of emotional disclosure writing that are seen in adult populations. Further studies aimed at examining these differences are thus warranted. 
Emotional Disclosure and Health 70

References

Abramovitch, R, Freedman, J. L., Thoden, K., \& Nikolich, C. (1991). Children's capacity to consent to participation in psychological research: Empirical findings. Child Development, 62. 1100-1109.

Barerra, M., Li, S. A., \& Chassin, L. (1995). Effects of parental alcoholism and life stress on Hispanic and Non-Hispanic Caucasian Adolescents: A prospective study. American Journal of Community Psychology, 23(4). 479-507.

Black. C. (1982). It will never happen to me. Denver, CO: MAC Publications.

Bonanno, G. A., \& Singer, J. L. (1990). Repressive personality style. In J. L. Singer (Ed.), Repression and dissociation. Chicago, IL: The Chicago University Press.

Bootzin. R. R. (1997). Examining the theory and clinical utility of writing about emotional experiences. American Psychological Society, 8(3), 167-169.

Booz-Allen \& Hamilton. Inc. (1974). An assessment of the needs of and resources for children of alcoholic parents (Report PB-241-119). Rockville, MD: National Institute on Alcohol Abuse and Alcoholism.

Brown. S., \& Lewis. V. (1999). The alcoholic family in recovery: A developmental model. New York: Guildford Press.

Carlson. N. R. (1999). Foundations of physiological psychology (4 $4^{\text {th }}$ ed.). Boston: Allyn and Bacon.

Charland, H., \& Cote, G. (1998). The children of alcoholics screening test (CAST): Testretest reliability and concordance validity. Jourmal of Clinical Psychology, 54(7), 995-1003.

Clendenon-Wallen. J. (1991). The use of music therapy to influence the self-confidence 
and self-esteem of adolescents who are sexually abused. Music Therapy Perspectives, 9, 73-81.

Cole, S. W., Kemeny, M. W., Taylor, S. E., \& Visscher, B. R. (1996). Elevated health risk among gay men who conceal their homosexual identity. Health Psychology, 15, 243-251.

Dienstfrey, H. (1999). Disclosure and health: An interview with James W. Pennebaker. Advances in Mind-Bodv Medicine, 15, 161-195.

Emshoff. J. G., \& Price. A. W. (1999). Prevention and intervention strategies with children of alcoholics. Pediatrics, 103(5), 1112-1121.

Feldman, R. S. (1998). Child development. Upper Saddle River: NJ: Prentice Hall.

Folkman. S.. \& Lazarus, R. S. (1988). Coping as a mediator of emotion. Journal of Personality and Social Psychology, 54. 466-475.

Goodman. R. (1997). The strengths and difficulties questionnaire: A research note. Journal of Child Psychology and Psychiatry, 38(5). 581-586.

Greenberg. M. A.. \& Stone, A. A. (1992). Emotional disclosure about traumas and its relation to health: Effects of previous disclosure and trauma severity. Journal of Personality and Social Psvchology, 63. 75-84.

Greenberg, M. A., Wortman, C. B.. \& Stone, A. A. (1996a). Emotional expression and physical health: Revisiting traumatic memories or fostering self-regulation? Journal of Personality and Social Psychology, 71(3), 588-602.

Greenberg, M. A. Wortman, C. B., \& Stone. A. A. (1996b). Health and psychological effects of emotional disclosure: A test of the inhibition-confrontation approach. Jourmal of Personality and Social Psychology, 71 , 588-602.

Harris. P. L. (1989). Children and emotion: The development of psychological understanding. New York: Basil Blackwell Ltd. 
Emotional Disclosure and Health 72

Harter, S. L. (2000). Psychosocial adjustment of adult children of alcoholics: A review of the recent empirical literature. Clinical Psychology Review, 20(3), 311-337.

Harnish. R. J, Sullivan. L. (1987, August). Body Image, Self-Monitoring, and Gender. Paper presented at the Annual Convention of the American Psychological Association. New York. NY.

Haviland, J. M., Davidson, R. B., Ruetsch, C., Gebelt, J. L; et al. (1994). Journal of Research on Adolescence, 4(4), 503-518.

Horowitz, M. J. (1976). Stress response sundromes. New York: Jacob Aronson.

Horowitz. M. J.. Wilner, N.. \& Alvarez, W. (1979). Impact of events scale: A measure of subjective stress. Psychological Medicine, 41, 209-218.

Jones. J. W. (1983). The children of alcoholics screening test. Bulletin of the Society of Psvchologists in Addictive Behaviors, $2,155-163$.

Jourard. S. M. (1971). Self-disclosure: An experimental analysis of the transparent self. New York: Wiley-Interscience.

Jourard. S. M. (1959). Healthy personality and self-disclosure. Mental Hygiene. New York. 43. 1959.

Kashubeck. S. (1994). Adult children of alcoholics and psychological distress. Journal of Counseling and Development, 72 , 538-543.

Kemper, R. L., \& Vernooy, A. R. (1994). Metalinguistic awareness in first graders: A qualitative perspective. Journal of Psycholinquistic Research, 22, 41-57.

Kloss. J. D. (1998). The effects of narrative disclosure on affect and health: A replication and extension of Pennebaker's model of inhibition Dissertation Abstracts Imtemational: Section B: 
The Sciences \& Engineering. Vol 59(4-B), pp. 1856.

Krantz, A., \& Pennebaker, J. W. (1995). Bodily versus written expression of traumatic experience. Manuscript submitted for publication.

Lawson, A., \& Lawson, G. (1998). Alcoholism and the family: A guide to treatment and prevention ( $2^{\text {nd }}$ ed.). Gaithersburg, MD: Aspen Publication.

Lawton, M. P.. Kleban, M. H., Dean. J. (1993). Affect and age: Cross-sectional comparisons of structure and prevalence. Psychology and Aging, 8(2), 165-175.

Lawton, M. P.. Kleban, M. H., Rajagopal, D., Dean, J. (1992). Dimensions of affective experience in three age groups. Psychology and Aging, 7(2), 171-184.

McNamee, J. E., \& Offord, D. R. (1994). Children of alcoholics. In Canadian Task Force on the Periodic Health Examination. Canadian Guide to Clinical Preventive Health Care (pp. 470485). Ottawa ON: Health Canada.

Meichenbaum. D. (1977). Cognitive-behavior modification: An integrative approach. New York: Plenum Press.

Merrell. K. W. (2000). Personal communication, October 16.

Merrell, K. W.. Crowley, S. L. \& Walters, A. S. (1997). Development and factor structure of a self-report measure for assessing internalizing symptoms of elementary-age children. Psychology in the Schools, 34(3), 197-210.

Moos. R. H.. \& Billings, A. G. (1992). Children of alcoholics during the recovery process: Alcoholic and matched control families. Addictive Behaviors, 7, 155-163.

Musser. L. M.. \& Browne, B. A. (1991). Self-monitoring in middle childhood: Personality and social correlates. Developmental Psychology_ 27(6), 994-99.

Nuechterlein, A. M. (1993). Families of alcoholics: A quide to recoverv and healing. 
Minneapolis, MN: Augsburg Fortress.

Paez D., Velasco, C., \& Gonzalez, J. L. (1999). Expressive writing and the role of alexyrhimia as a dispositional deficit in self-disclosure and psychological health. Journal of Personalitv and Social Psvchology. 77(3), 630-641.

Pennebaker. J. W. (1982). The psychology of physical symptoms. New York: SpringerVerlag.

Pennebaker. J. W. (1985). Traumatic experience and psychosomatic disease: Exploring the roles of behavioural inhibition, obsession, and confiding. Canadian Psychology, 26(2), 82-95.

Pennebaker. J. W. (1989). Confession. inhibition, and disease. In L. Berkowitz (Eds), Advances in Experimental Social Psychology, Vol. 22 (pp.211-244). New York: Academic Press.

Pennebaker. J. W. (1990). Opening up: The healing power of confiding in others. New York: Morrow.

Pennebaker. J. W. (1993). Putting stress into words: Health. linguistic. and therapeutic implications. Behavior Research Therapy, 31(6), 539-548.

Pennebaker. J. W. (1995). Emotion, disclosure and health. Washington. DC: American Psychological Association.

Pennebaker. J. W. (1997a). Opening up: The bealing power of expressing emotions. New York: The Guildford Press.

Pennebaker. J. W. (1997b). Writing about emotional experiences as a therapeutic process. Psvchological Science, 8(3), 162-166.

Pennebaker, J. W.. Barger, S. D.. \& Tiebout, J. (1989). Disclosure of traumas and health among Holocaust survivors. Psychosomatic Medicine, 51, 577-589.

Pennebaker, J. W.. \& Beall, S. K. (1986). Confronting a traumatic event: Toward an 
understanding of inhibition and disease. Journal of Abnormal Psychology, 95, 274-281.

Pennebaker, J. W., Burnam, M. A., Schaeffer, M. A., \& Harper, D. C. (1977). Lac of control as a determinant of perceived physical symptoms. Journal of Personalitv and Social Psychology, 35, 167-174.

Pennebaker. J. W.. Colder, M., \& Sharp, L. K. (1990). Accelerating the coping process. Journal of Personality and Social Psychology, 58(3), 528-537.

Pennebaker. J. W.. \& Francis. M. (1996). Cognitive, emotional. and language processes in disclosure. Cognition and Emotion, 10, 601-626.

Pennebaker. J. W.. \& Francis. M. (1999). Linquistic Inquiry and Word Count: LIWC. Mahwah. NJ: Erlbaum.

Pennebaker. J. W.. \& Graybeal. A. (in press). Patterns of natural language use: Disclosure, personality, and social integration. Current Directions.

Pennebaker. J. W.. Hughes, C. F.. \& O'Heeron. R. C. (1987). The psychophysiology of confession: Linking inhibitory and psychosomatic processes. Journal of Personality and Social Psychology, 52. 781-793.

Pennebaker. J. W.. Kiecolt-Glaser. J. K.. \& Glaser. R. (1988). Disclosure of traumas and immune function: Health implications for psychotherapy. Journal of Consulting and Clinical Psvchology, 56. 239-245.

Pennebaker. J. W.. \& King. L. A. (1999). Linguistic style: Language use as an individual difference. Journal of Personality and Social Psychology, 77(6), 1296-1312.

Pennebaker, J. W.. Mayne, T. J., \& Francis, M. E. (1997). Linguistic predictors of adaptive bereavement. Journal of Personality and Social Psychology, 72, 863-871.

Pennebaker. J. W., \& O'Heeron, R. C. (1984). Confiding in others and illness rates among 
Emotional Disclosure and Health 76

spouses of suicide and accidental death. Journal of Abnormal Psychology, 93, 473-476.

Pennebaker, J. W., Zech, E., \& Rime, B. (in press). Disclosing and sharing emotion:

Psychological social and health consequences. In M. S. Stroebe, R. O. Hansson, W. Stroebe. \& H. Schut (Eds.), Handbook of bereavement research: Consequences, coping, and care.

Washington, DC: American Psychological Association.

Petrie, K. J.. Booth, R. J., Pennebaker, J. W., Davison, K. P., \& Thomas, M. G. (1995).

Disclosure of trauma and immune response to a hepatitis B vaccination program. Joumal of Consulting and Clinical Psychology.63, 787-792.

Pilat. J. M.. \& Jones, J. W. (1985). Identification of children of alcoholics -Two empirical studies. Alcohol and Research World, 9, 27-33.

Purdon C. (1999). Thought suppression and psychopathology. Behavior Research and Therapy, 37, 1029-1054.

Rawlings. W. (1983). Openness as problematic in ongoing relationships: Two conversational dilemmas. Communication Monographs, 50, 1-13.

Reinert. D. F. (1999). Group intervention for children of recovering alcoholic parents. Alcoholism Treatment Quarterty, 17(4). 15-27.

Reynolds. M., Brewin. C. R. Saxton. M. (2000). Emotional disclosure in school children. Journal of Child Psychology and Psychiatry and Allied Disciplines, 41(2). 151-159.

Richards, J. M. Pennebaker. J. W., \& Beal, W. E. (1995). The effects of criminal offense and disclosure of trauma on anxiety and illness in prison inmates. Paper presented at the annual meeting of the Midwest Psychological Association Chicago, IL.

Robinson. B. E. \& Rhoden, J. L. (1998). Working with children of alcoholics: The practitioner's handbook. Thousand Oaks, CA: SAGE Publications. 
Emotional Disclosure and Health 77

Roosa. M. W.. Beals. J., Sandler. I. N., \& Pillow, D. R. (1990). The role of risk and protective factors in predicting symptomatology in adolescent self-identified children of alcoholic parents. American Journal of Community Psychology, 18(5), 725-741.

Roosa M. W., Sandler, I. N.. Beals. J., \& Short. J. L. (1988). Risk status of adolescent children of problem-drinking parents. American Journal of Community Psychology, 16, 225-239.

Rubenstein M. W. (1982). Wellness is all: A report on Psychology Today's survey of beliefs about health. Psvchology Today, 16, 28-37.

Russell, M., Henderson, C., \& Blume, S. B. (1985). Children of alcoholics: A review of the literature. New York: Children of Alcoholics Foundation.

Schulsinger. J.. Korp. J., Goodwin. D. W., Teasdale. T. W.. \& Mikkelson. U. (1986). A prospective study of young men at high risk for alcoholism. Archives of General Psychiatry, 43 , 755-760.

Schwartz. G. E. (1990). Psychobiology of repression and health: A systems approach. In J. L. Singer (Ed.), Repression and dissociation. Chicago: The Chicago University Press.

Seyle. H. (1976). The stress of life. New York: McGraw-Hill.

Sher. K. J. (1991). Children of alcoholics: A critical appraisal of theory and research. Chicago: Chicago University Press.

Silver, R. L.. \& Wortman, C. B. (1980). Coping with undesirable life events. In J. Garber \& M. E. P. Seligman (Eds.), Human helplessness theory and applications (pp. 279-375). New York: Academic Press.

Smyth. J. M. (1998). Written emotional expression: Effect sizes. outcome types. and moderating variables. Journal of Consulting and Clinical Psycholory, 66(1), 174-184. 
Emotional Disclosure and Health 78

Springer, K., \& Pennebaker. J. W. (1995). Written disclosure as a means of stress reduction in children. Manuscript submitted for publication.

Steinhausen, H. C., Nestler, V.. \& Huth. H. (1982). Psychopathology in the offspring of alcoholic and epileptic mothers. Journal of the American Academv of Child and Adolescent Psychiatry, 32, 990-994.

Taylor, S. E. (1999). Health Psychology (4 $4^{\text {th }}$ Ed.). Boston: McGraw Hill.

Watson. D.. Clark. A. L. \& Tellegen, A. (1988). Development and validation of brief measures of positive and negative affect: The PANAS scales. Journal of Personality and Social Psvchology, 54(6), 1063-1070.

Wegner, D. M., Shortt, J. W., Blaker, A. W., \& Page. M. S. (1990). The suppression of thoughts of a past reiationship. Journal of Personality and Social Psychology, 54(6), 1063-1070.

Wegner. D. M.. \& Zanakos. S. (1994). Chronic thought suppression. Journal of Personality, 62. 615-640.

Wolfson. D. K. (1973). Non-linguistic factors in language. Communication and Cognition. $\underline{6}(2), 45-52$.

Zilberg. N. J.. Weiss. D. S., \& Horowitz. M. J. (1982). Impact of event scale: A crossvalidation study and some empirical evidence supporting a conceptual model of stress response syndromes. Journal of Consulting and Clinical Psychology, 50, 407-414. 
Appendix A

\section{Participant (Youth) Demographic Questionnaire}

Please answer the questions below. Write in your answers on the black lines except where it asks your to circle your answer.

1. When is your birthday? Please give the month and year (ex. March 5).

Month

Day

2. What ser are you?

Male (boy)

Female (girl)

3. How old are you in years?

(ex. I am 14 years old)

I am ___ years old.

4. Which of the following are you?

Only child

Oldest child

Middle child

Youngest child

5. Are your parents...

Please circle your answer

Married

Separated

Living together

Remarried

Unsure

6. Do you keep a diary or journal?

(Please circle your answer)

YES NO
7. Who do you live with?

I live with my mother and father

I live with my mother

I live with my father

I live with

8. Are you part of any youth groups?

(Circle your answer)

YES NO

8.b. If you are part of a youth group. what is the name of it? (i.e. Brentwood Youth Group)

9. Do you see any of the following people? (Circle your answer)

School counselor YES NO Social worker YES NO Doctor YES NO

9.b. If you see any of these people. what do you see them for? 
Appendix B

Pareatal Demographic Questionnaire

In this study, some important information from parents is required. Your answering the questions below will help to give a better picture of the people taking part in this study. Please circle the answer which applies to you.

1. What is the race or ethnic background of your child?
African-Canadian
Asian
Caucasian (White)
Native Canadian
Other (please specify)

2. What is your yearty income (circle)

Less than $\$ 10.000$

$\$ 10,000 \cdot \$ 20.000$

$\$ 20.000 \cdot \$ 30.000$

$\$ 30.000-\$ 40,000$

$\$ 40.000-\$ 50.000$

$\$ 50.000-\$ 60.000$

$\$ 60.000-\$ 70.000$

$\$ 70.000$ and over

3. What is your current marital status?

Please circle one.

\section{Single}

Married

Divorced

Separated

Remarried

Other

4. Is your child currently receiving any counseling (i.e. seeing a school counselor. social worker. therapist)

YES NO

If yes, please specify who your child sees
5. Has your child received counseling in the past (i.e. a school counselor. social worker, therapist)?

YES NO

If yes. please specify

6. Does your child have a learning disability?

YES NO

6.b. If you answered yes. what type of learning disability does your child have? (i.e. dyslexia)

7. Does your child have any type of medical condition?

YES NO

7.b. If you answered yes, what is the medical condition your child has?

8. Is your child currently on any kind of medication?

YES NO

8.b. If yes, what kind of medication are they taking right now? 
Appendix C

\section{Children of Alcoholies Sereening Test (CAST)}

Please check $(\mathcal{})$ the answer below that best describes your feelings, behaviors, and experiences related to a parent's alcohol use. Take your time

\begin{tabular}{|c|c|c|c|}
\hline \multicolumn{2}{|c|}{ QUESTION } & \multirow[t]{2}{*}{ YES } & \multirow[t]{2}{*}{ No } \\
\hline 1. & $\begin{array}{l}\text { Have you ever thought that one of your parents had a drinking } \\
\text { problem? }\end{array}$ & & \\
\hline 2. & Have you ever lost sleep because of a parent's drinking? & & \\
\hline 3. & Did you ever encourage one of your parents to quit drinking? & & \\
\hline 4. & Did you ever feel alone, scared, nervous, angry, or frustrated? & & \\
\hline 5. & $\begin{array}{l}\text { Did you ever argue or fight with a parent when he or she was } \\
\text { drinking? }\end{array}$ & & \\
\hline 6. & $\begin{array}{l}\text { Did you ever threaten to run away from home because of a parent's } \\
\text { drinking problem? }\end{array}$ & & \\
\hline 7. & $\begin{array}{l}\text { Has a parent ever yelled at or hit you or other family members when } \\
\text { drinking? }\end{array}$ & & \\
\hline 8. & Have you ever heard your parents fight when one of them was drunk? & & \\
\hline 9. & $\begin{array}{l}\text { Did you ever protect another family member from a parent who was } \\
\text { drinking? }\end{array}$ & & \\
\hline 10. & Did you ever feel like hiding or emptying a parent's bottle of liquor? & & \\
\hline 11. & $\begin{array}{l}\text { Do many of your thoughts revolve around a problem drinking parent or } \\
\text { difficulties that arise because of his or her drinking? }\end{array}$ & & \\
\hline 12. & Did you ever wish that a parent would stop drinking? & & \\
\hline 13. & $\begin{array}{l}\text { Did you ever feel responsible for and guilty about a parent's } \\
\text { drinking? }\end{array}$ & & \\
\hline 15. & $\begin{array}{l}\text { Have you ever withdrawn from and avoided outside activities and friends } \\
\text { because of embarrassment and shame over a parent's drinking problem? }\end{array}$ & & \\
\hline 14. & Did you ever fear that your parents would get divorced due to alcohol misuse? & & \\
\hline 16. & $\begin{array}{l}\text { Did you ever feel caught in the middle of an argument or fight between a } \\
\text { problem-drinking parent and your other parent? }\end{array}$ & & \\
\hline
\end{tabular}




\begin{tabular}{|c|c|c|c|}
\hline \multicolumn{2}{|c|}{ QUESTION } & \multirow[t]{2}{*}{ YES } & \multirow[t]{2}{*}{ No } \\
\hline 17. & Did you ever feel that you made a parent drink alcohol? & & \\
\hline 18. & Have you ever felt that a problem-drinking parent did not really love you? & & \\
\hline 19. & Did you ever resent a parent's drinking? & & \\
\hline 20. & $\begin{array}{l}\text { Have you ever worried about a parent's health because of his or her alcohol } \\
\text { use? }\end{array}$ & & \\
\hline 21. & Have you ever been blamed for a parent's drinking? & & \\
\hline 22. & Did you ever think your father was an alcoholic? & & \\
\hline 23. & $\begin{array}{l}\text { Did you ever wish your home could be more like the homes of your friends who } \\
\text { did not have a parent with a drinking problem? }\end{array}$ & & \\
\hline & $\begin{array}{l}\text { Did a parent ever make promises to you that he or she did not keep because of } \\
\text { drinking? }\end{array}$ & & \\
\hline 25. & Did you ever think your mother was an alcoholic? & & \\
\hline & $\begin{array}{l}\text { Did you ever wish that you could talk to someone who could understand and } \\
\text { help the alcohol-related problems in your family? }\end{array}$ & & \\
\hline 27. & Did you ever fight with your brothers and sisters about a parent's drinking? & & \\
\hline & $\begin{array}{l}\text { Did you ever stay away from home to avoid the drinking parent or your other } \\
\text { parent 's reaction to the drinking? }\end{array}$ & & \\
\hline & $\begin{array}{l}\text { Have you ever felt sick. cried. or had a "knot" in your stomach after worrying } \\
\text { about a parent's drinking? }\end{array}$ & & \\
\hline & $\begin{array}{l}\text { Did you ever take over any chores and duties at home that were usually done } \\
\text { by a parent before he or she developed a drinking problem? }\end{array}$ & & \\
\hline
\end{tabular}

Jones. J. W. (1983). The children of alcoholics screening test and test manual. Chicago. IL: Camelot Unlimited. 
Appendix D

Impact of Event Scale (IES)

This is the event I wrote about

The event I wrote about occurred on (include month and year).

Below is a list of comments made by people after stressful life events. Please check each item. indicating how frequently these comments were true for you during the past seven days. If they did not occur during that time. please mark the "not at all" column.

\begin{tabular}{|c|c|c|c|c|c|}
\hline & & Not at all & Rarely & Sometimes & Often \\
\hline 1. & I thought about it when I didn't mean to. & & & & \\
\hline 2. & I thought about it or was reminded of it. & & & & \\
\hline 3. & I tried to remove it from memory. & & & & \\
\hline 4. & $\begin{array}{l}\text { I had trouble falling asleep or staying asleep, } \\
\text { because of pictures or thoughts about it that } \\
\text { came into my mind. }\end{array}$ & & & & \\
\hline 5. & I had waves of strong feelings about it. & & & & \\
\hline 6. & I had dreams about it. & & & & \\
\hline 7. & I stayed away from reminders of it. & & & & \\
\hline 8. & I felt as if it hadn't happened or it wasn't real. & & & & \\
\hline 9. & I tried not to talk about it. & & & & \\
\hline 10. & Pictures about it popped into my mind. & & & & \\
\hline 11. & Other things kept making me think about it. & & & & \\
\hline 12. & $\begin{array}{l}\text { I was aware that I still had a lot of } \\
\text { feelings about it, but I didn't deal with them. }\end{array}$ & & & & \\
\hline 13. & I tried not to think about it. & & & & \\
\hline 14. & Any reminder brought back feelings about it. & & & & \\
\hline 15. & My feelings about it were kind of numb. & & & & \\
\hline
\end{tabular}

Horowitz. M. Wilner, N, \& Alvarez. W. Impact of event scale: A measure of subjective stress. Psychosomatic Medicine, 41(3), 209-218. 
Appendix $\mathrm{E}$

\section{Subjective Evaluation of Essay (SEL)}

Please think about the essay you just wrote and answer the following questions.

For example, if your feel that what you wrote about was really important and meaningful then you would place a checkmark $(\sqrt{ })$ in the box under "A great deal"

\begin{tabular}{|c|c|c|c|c|c|c|}
\hline & & $\begin{array}{l}\text { Not at } \\
\text { all }\end{array}$ & A little & Moderately & $\begin{array}{l}\text { Quite } \\
\text { a bit }\end{array}$ & $\begin{array}{l}\text { A great } \\
\text { deal }\end{array}$ \\
\hline 1. & $\begin{array}{l}\text { Was your essay personally } \\
\text { meaningful? (i.e. was it } \\
\text { important to you) }\end{array}$ & & & & & \\
\hline 2. & $\begin{array}{l}\text { In your essay did you describe } \\
\text { or talk about your emotions? }\end{array}$ & & & & & \\
\hline 3. & $\begin{array}{l}\text { Was your essay something you } \\
\text { wanted to talk to others about? }\end{array}$ & & & & & \\
\hline 4. & $\begin{array}{l}\text { Was your essay something you } \\
\text { have talked to others about? }\end{array}$ & & & & & \\
\hline
\end{tabular}

Please answer this question by circling the best answer.

5. Did the event you wrote about actually happen to you? 


\section{Appendix F \\ Internalizing Symptoms Seale for Adolescents (ISSA)}

The following sentences tell some ways that teenagers might sometimes feel. Read each of these sentences and decide how often they are true for you. Ask yourself, "Is this Never true, Hardly Ever true. Sometimes true, or Often true for me?'. After you have decided how often the sentence is true for you. make an $\mathbf{X}$ in the box that goes with that answer. There are no right or wrong answers, just choose the answer that tells how you feel.

\begin{tabular}{|c|c|c|c|c|c|}
\hline \multicolumn{2}{|c|}{ How true is this for me? } & \multirow[t]{2}{*}{ Never True } & \multirow{2}{*}{$\begin{array}{l}\text { Hardly Ever } \\
\text { True }\end{array}$} & \multirow{2}{*}{$\begin{array}{l}\text { Sometimes } \\
\text { True }\end{array}$} & \multirow{2}{*}{$\begin{array}{l}\text { Onen } \\
\text { True }\end{array}$} \\
\hline 1. & I am shy & & & & \\
\hline 2. & I worry about things & & & & \\
\hline 3. & I feel cheerful & & & & \\
\hline 4. & I have bad dreams & & & & \\
\hline 5. & I feel important & & & & \\
\hline 6. & Things are hard for me & & & & \\
\hline 7. & I feel lonely & & & & \\
\hline 8. & I worry that I will hurt someone & & & & \\
\hline 9. & I have lots of energy & & & & \\
\hline 10. & I have trouble sleeping & & & & \\
\hline II. & I feel like I might faint & & & & \\
\hline 12. & I get upset easily & & & & \\
\hline 13. & I am good at lots of things & & & & \\
\hline & $\begin{array}{l}\text { I feel like I have made too many } \\
\text { mistakes }\end{array}$ & & & & \\
\hline & Lots of things scare me & & & & \\
\hline 16. & Other people like me & & & & \\
\hline 17. & I feel like crying & & & & \\
\hline & $\begin{array}{l}\text { When there is a problem it is my } \\
\text { fault }\end{array}$ & & & & \\
\hline 19. & I have a difficult time breathing & & & & \\
\hline
\end{tabular}




\begin{tabular}{|c|c|c|c|c|c|}
\hline \multicolumn{2}{|c|}{ How true is this for me? } & \multirow[t]{2}{*}{ Never True } & \multirow{2}{*}{$\begin{array}{l}\text { Hardly Ever } \\
\text { True }\end{array}$} & \multirow{2}{*}{$\begin{array}{l}\text { Sometimes } \\
\text { True }\end{array}$} & \multirow{2}{*}{$\begin{array}{l}\text { Onten } \\
\text { True }\end{array}$} \\
\hline 20. & $\begin{array}{l}\text { I do things as well as other people my } \\
\text { age }\end{array}$ & & & & \\
\hline 21. & $\begin{array}{l}\text { I worry that something bad will } \\
\text { happen }\end{array}$ & & & & \\
\hline 22. & I am comfortable with the way I look & & & & \\
\hline 23. & I feel sad & & & & \\
\hline 24. & I get scared for no reason & & & & \\
\hline 25. & I feel sick to my stomach & & & & \\
\hline 26. & $\begin{array}{l}\text { I laugh and smile as much as other } \\
\text { people }\end{array}$ & & & & \\
\hline 27. & I feel restless & & & & \\
\hline & $\begin{array}{l}\text { I would rather be alone than with } \\
\text { other people }\end{array}$ & & & & \\
\hline & $\begin{array}{l}\text { I have a hard time concentrating on } \\
\text { things }\end{array}$ & & & & \\
\hline 30. & I feel sorry for myself & & & & \\
\hline 31. & My feelings get hurt easily & & & & \\
\hline 32. & I don't enjoy anything & & & & \\
\hline & $\begin{array}{l}\text { I have a hard time making up my } \\
\text { mind }\end{array}$ & & & & \\
\hline 34. & I think about hurting myself & & & & \\
\hline 35. & I do well in school & & & & \\
\hline 36. & It seems like no one cares about me & & & & \\
\hline & I feel happy & & & & \\
\hline 38. & I feel very tired & & & & \\
\hline 39. & I don't feel like doing anything & & & & \\
\hline 40. & I like myself & & & & \\
\hline & $\begin{array}{l}\text { I worry that other people will not like } \\
\text { the way I do things }\end{array}$ & & & & \\
\hline
\end{tabular}




\begin{tabular}{|c|c|c|c|c|c|}
\hline \multicolumn{2}{|c|}{ How true is this for me? } & \multirow[t]{2}{*}{ Never True } & \multirow{2}{*}{$\begin{array}{l}\text { Hardly Ever } \\
\text { True }\end{array}$} & \multirow{2}{*}{$\begin{array}{l}\text { Sometimes } \\
\text { True }\end{array}$} & \multirow{2}{*}{$\begin{array}{l}\text { Onten } \\
\text { True }\end{array}$} \\
\hline & $\begin{array}{l}\text { I hate it when I am the center of } \\
\text { attention }\end{array}$ & & & & \\
\hline 43. & Bad things happen to me & & & & \\
\hline 44. & I think about dying & & & & \\
\hline 45. & My hands and feet feel sweaty & & & & \\
\hline 46. & $\begin{array}{l}\text { I feel like doing things with other kids } \\
\text { my age }\end{array}$ & & & & \\
\hline 47. & I can't do anything right & & & & \\
\hline 48. & I feel nervous & & & & \\
\hline 49. & I get embarrassed easily & & & & \\
\hline 50. & I have lots of aches and pains & & & & \\
\hline 51. & $\begin{array}{l}\text { Sometimes I feel like I am going to } \\
\text { explode }\end{array}$ & & & & \\
\hline 52. & I feel confused & & & & \\
\hline 53. & I feel great & & & & \\
\hline 54. & $\begin{array}{l}\text { I believe things will turn out okay for } \\
\text { me }\end{array}$ & & & & \\
\hline 55. & I feel guilty & & & & \\
\hline 56. & I feel terrible when I make mistakes & & & & \\
\hline 57. & I don't give up when things get tough & & & & \\
\hline 58. & $\begin{array}{l}\text { Things I used to like aren't fun } \\
\text { anymore }\end{array}$ & & & & \\
\hline 59. & I'm afraid that I will fail & & & & \\
\hline 60. & $\begin{array}{l}\text { ['m not as good as my parents want me } \\
\text { to be }\end{array}$ & & & & \\
\hline 61. & I try again when I lose & & & & \\
\hline 62. & $\begin{array}{l}\text { It feels like I have a lump in my } \\
\text { throat }\end{array}$ & & & & \\
\hline 63. & I feel calm and relaxed & & & & \\
\hline
\end{tabular}

Merrell. K. W. (2000). Personal communication. October 16. 


\section{Appendix G}

The Positive and Negative Aftect Scale (PANAS)

This scale consists of words that describe different feelings and emotions. Read each item and then mark the appropriate answer in the space next to that word. Indicate to what extent you feel this way, RIGHT NOW, that is, at the present moment.

\begin{tabular}{|c|c|c|c|c|c|c|}
\hline & & $\begin{array}{l}\text { Very slighty } \\
\text { or not af all }\end{array}$ & A little & Moderately & Quite a bit & Extremeły \\
\hline 1. & Interested & & & & & \\
\hline 2. & Distressed & & & & & \\
\hline 3. & Excited & & & & & \\
\hline 4. & Upset & & & & & \\
\hline 5. & Strong & & & & & \\
\hline 6. & Guilty & & & & & \\
\hline 7. & Scared & & & & & \\
\hline 8. & Hostile & & & & & \\
\hline 9. & Enthusiastic & & & & & \\
\hline 10. & Proud & & & & & \\
\hline 11. & Irritable & & & & & \\
\hline 12. & Alert & & & & & \\
\hline 13. & Ashamed & & & & & \\
\hline 14. & Inspired & & & & & \\
\hline 15. & Nervous & & & & & \\
\hline 16. & Determined & & & & & \\
\hline 17. & Attentive & & & & & \\
\hline 18. & Jittery & & & & & \\
\hline 19. & Active & & & & & \\
\hline 20. & Afraid & & & & & \\
\hline
\end{tabular}

Watson. D.. Clark. L. A., \& Tellegen. A. (1988). Development and validation of brief measures of positive and negative affect: The PANAS scales. Journal of Personality and Social Psychology, 54, $1063-1070$. 


\section{Appendix $\mathrm{H}$ \\ Strengths and Difificulties Questionnaire (SDQ)}

For each item. please mark the box $(\checkmark)$ for Not True, Somewhat True or Certainly True. It would help us if you inswered all items as best you can even if you are not absolutely certain of the answer.

\begin{tabular}{|c|c|c|c|c|}
\hline & & $\begin{array}{l}\text { Not } \\
\text { True }\end{array}$ & $\begin{array}{l}\text { Somewhat } \\
\text { True }\end{array}$ & $\begin{array}{l}\text { Certainly } \\
\text { True }\end{array}$ \\
\hline 1. & I try to be nice to other people & & & \\
\hline 2. & I am restless. I cannot stay still for long & & & \\
\hline 3. & I get a lot of headaches, stomach-aches or sickness & & & \\
\hline 4. & I usually share with others (food. games, pens. etc) & & & \\
\hline 5. & I get very angry and often lose my temper & & & \\
\hline 6. & I am usually on my own. I generally play alone or keep to myself & & & \\
\hline 7. & I usually do as I am told & & & \\
\hline 8. & I worry a lot & & & \\
\hline 9. & I am helpful if someone is hurt. upset or feeling ill & & & \\
\hline 10. & I am constantly fidgeting or squirming & & & \\
\hline 11. & I have one good friend or more & & & \\
\hline 12. & I fight a lot. I can make other people do what I want & & & \\
\hline 13. & I am often unhappy, down-hearted or tearful & & & \\
\hline 14. & Other people my age generally like me & & & \\
\hline 15. & I am easily distracted. I find it difficult to concentrate & & & \\
\hline 16. & I am nervous in new situations. I easily lose confidence. & & & \\
\hline 17. & I am kind to younger children & & & \\
\hline 18. & I am often accused of lying or cheating & & & \\
\hline 19. & Other children or young people pick on me or bully me & & & \\
\hline 20. & I often volunteer to help others (parents. teachers. children) & & & \\
\hline 21. & I think before I do things & & & \\
\hline 22. & I take things that are not mine from home, school or elsewhere & & & \\
\hline 23. & I get on better with adults than with people my own age & & & \\
\hline
\end{tabular}




\begin{tabular}{|l|l|l|l|}
\hline & $\begin{array}{l}\text { Not } \\
\text { True }\end{array}$ & $\begin{array}{l}\text { Somewhat } \\
\text { True }\end{array}$ & $\begin{array}{l}\text { Certainly } \\
\text { True }\end{array}$ \\
\hline 24. I have many fears. I am easily scared & & & \\
\hline 25. I finish the work I'm doing. My attention is good & & & \\
\hline
\end{tabular}

Goodman. R (1997). The strengths and difficulties questionnaire: A research note. Journal of Child Psychology ind Psvchiatry, 38(5). 581-586. 
Appendix I

\section{Pennbaker's Limbic Languidneas Scale (PILL)}

Several common symptoms or bodily sensations are listed below. Most people have experienced most of them at one time or another. We are currently interested in finding out how prevalent each symptom is among various groups of people. On the page below, write how frequently you experience each symptom. For all items. Use the following scale:

For example, if your nose tends to bleed once every week you would place a " $D$ " next to bleeding nose.

1. Eyes Water
2. Itchy eyes or skin
3. Ringing in ears
4. Temporary deafness or hard of
hearing
5. Lump in throat
6. Choking sensations
7. Sneezing spells
8. Running nose
9. Congested nose
10. Bleeding nose
11. Asthma or wheezing
12. Coughing
13. Out of breath
14. Swollen ankles
15. Chest pains
16. Racing heart
17. Cold hands or feet even in hot
weather
18. Leg cramps
19. Insomnia or difficulty sleeping
20. Toothaches
21. Upset stomach
22. Indigestion
23. Heartburn or gas
24. Abdominal pain
25. Diarthea
26. Constipation
27. Hemorrhoids

\section{Swollen joints}

29. Stiff or sore muscles

30. Back pains

31. Sensitive or tender skin

32. Face flushes

33. Tightness in chest

34. Skin breaks out in rash

35. Acne or pimples on face

36. Acne/pimples other than face

37. Boils

38. Sweat even in cold weather

39. Strong reactions to insect bites

40. Headaches

41. Feeling pressure in head

42. Hot flashes

43. Chills

44. Dizziness

45. Feel faint

46. Numbness or tingling in any part of body

47. Twitching of eyelid

48. Twitching other than eyelid

49. Hands tremble or shake

50. Stiff joints

51. Sore muscles

52. Sore throat

53. Sunburn

54. Nausea

Pennebaker. J. W. (1982). The psychology of physical symptoms. New York: SpringerVerlag. 


\section{Appendix J \\ Participant Assent Form A (Intervention Group)}

Researchers at the University of Windsor are interested in understanding what happens when young people write about things that have happened in their lives. So, we are interested in finding out what kind of things happen when you keep a journal in which you must write about certain things.

In order to study about journal writing. we need you to come in and give us some information. You will give us this information by filling out some forms. The forms have questions on them which ask you about your mood. behaviors, health. and attindes. You will also be asked things like how old you are and what grade you are in.

After you have finished filling out the forms you will be asked to write about certain topics. For three days in a row you will come in and write for 20-25 minutes about a certain topic. You will be given instructions on a piece of paper and from somebody who tells them to you out loud.

When you have finished 3 writing sessions you will be free to go. After one month has passed you will come back and answer some more questions about your mood, behaviors, health. and attitudes. The leader of the study will give tell you when to come back.

It is important that you know that the only person who will see what you write will be the leader of the study (M. Gallant). If the leader is seriously concerned about what you wrote then she will come and talk to you about it as well as make your parents aware of the situation. When you fill out the forms your name will NOT go on them. You will have to put your birthday on them however, so that we can make sure your forms all get put together. All of the completed forms will be kept by the leader of the study (M. Gallant) and her teacher (Dr. K. Lafreniere). You can skip any questions that you don't feel like answering, but you will be asked to answet as many things as you can. You can also quit the study at any time.

This study has been passed by the Ethics Committee of the Psychology Department. University of Windsor. Any concerns or questions about the ethics or procedures of this study may be directed to: Dr. Stewart Page. Chair. Ethics Commintee. Dept. Of Psychology, University of Windsor, (519) 253-3000 ext. 2243. listed below.

If you have any questions about the study. the researchers can be contacted at the phone numbers Thanks again for your help.

Leader of the study

Melanie D. Gallant, B. Sc., B.A. (Hons.)

Department of Psychology

University of Windsor

Tel. (519) 253-4232 ext. 2220
Faculty Advisor (Teacher)
Kathryn D. Lafreniere, Ph.D.
Department of Psychology
University of Windsor
Tel. (519) $253-4232$ ext. 2233

I have read and understand the attached information and agree to be a part of this study.

Sigped:

Date: 
Appendix J

\section{Participant Assent Form B (Control Group)}

Researchers at the University of Windsor are interested in learning about how young people think. feel. and behave in their everyday lives.

In order to study about this. we need you to come in and give us some information. You will give us this information by filling out some forms. The forms have questions on them which ask you about your mood. behaviors. health. and attitudes. You will also be asked things like how old you are and what grade you are in. You will be asked to come in two times. Both times you will be filling out questionnaires which ask you questions about yourself.

It is important that you know that the only person who will see your answers to the forms you fill out will be the leader of the study (M. Gallant). When you fill out the forms your name will NOT go on them. You will have to put your birthday on them however. so that we can make sure your forms all get put together. All of the completed forms will be kept by the leader of the study (M. Gallant) and her teacher (Dr. K. Lafreniere). You can skip any questions that you don't feel like answering, but you will be asked to answer as many things as you can. You can also quit the study at any time.

This study has been passed by the Ethics Committee of the Psychology Department. University of Windsor. Any concerns or questions about the ethics or procedures of this study may be directed to: Dr. Stewart Page. Chair, Ethics Committee. Dept. Of Psychology, University of Windsor, (519) 253-3000 ext. 2243. listed below.

If you have any questions about the study. the researchers can be contacted at the phone numbers

Thanks again for your help,

Leader of the study

Melanie D. Gallant. B. Sc., B.A. (Hons.)

Department of Psychology

University of Windsor

Tel. (519) 253-4232 ext. 2220
Faculty Advisor (Teacter)
Kathryn D. Lafreniere. Ph.D.
Department of Psychology
University of Windsor
Tel. (519) 253-4232 ext. 2233

I have read and understand the atrached information and agree to be a part of this study.
Signed:

Date: 
Appendix K

\section{Parental Consent Form (Intervention Group)}

Researchers at the University of Windsor are interested in looking at children of alcoholics. In particular, we are interested in examining the effects of a writing task on health outcomes in children of alcoholics between the ages of 10-17.

The writing task involves having youth write about events of a personal nature. During the first part of the study youth between the ages of 10-17 will be asked to complete a series of questionnaires which assess their mood. behaviors, attitudes and health. During the second part of the study, children of alcoholics will write for 20-25 minutes about events of a personal nature. After the 25 minutes of writing are up they will be asked to fill out additional questionnaires which measure mood states. The writing part will occur for three days in a row. thus participants will come in for a total of 3 writing sessions. After the last writing session participants will be given a one month follow-up appointment. During this follow-up appointment they will fill out the same questionnaires they filled out at the beginning of the study.

To assure confidentiality, participants' work will be coded by number. Participants will be assured that what they write will only be read by the primary investigator. If the participant's writing reveals serious concerns that need to be addressed however, the investigator will contact the parent and discuss these. Strict confidentiality will be maintained at all times during the study. Participants will be told that they may skip any questions that they do not feel comfortable answering, although they will be encouraged to answer all items on the questionnaires. Participants will also be informed both verbally and in the youth consent form that they may terminate their participation in the study at any time.

This research has been cleared by the Ethics Committee of the Psychology Department. University of Windsor. Any concerns about the ethics or procedures of this investigations may be directed to: Dr. Stewart Page, Chair. Ethics Committee. Dept. of Psychology. University of Windsor, (519) 253-3000. ext. 2243. listed below.

If you have any questions about this study. the researchers can be contacted at the phone numbers

Thank you for your consideration.

\section{Priacipal Investigator}

Melanie D. Gallant. B.Sc.. B.A. (Hons.)

Department of Psychology

University of Windsor

Tel. (519) 971-9489
Feculty Advicor

Kathryn D. Lafreniere. Ph.D.

Department of Psychology

University of Windsor

Tel. (519) 253-4232 ext. 2233

I have read the information attached and I consent to allow my son/daughter to participate in this project.

Signed:

Date: 


\section{Appendix K \\ Parental Consent Form B (Control Group)}

Researchers at the University of Windsor are interested in assessing how children of alcoholics think, feel, and behave. In particular, we are interested in examining mood. behavior, attitude and health in children of alcoholics between the ages of 10-17.

In order to study about this. we need youth between the ages of 10-17 to come in and give us some information. They will give us this information by filling out some questionnaires. These questionnaires will have questions which ask young people about their moods, behaviors. health. and attitudes. They will also be asked things like how old they are and what grade they are in. They will be asked to come in on two separate occasion to fill out the questionnaires.

To assure confidentiality, participants' answers will be coded by number. Participants will be assured that their answers will only be seen by the primary investigator. Strict confidentiality will be maintained at all times during the study. Participants will be told that they may skip any questions that they do not feel comfortable answering, although they will be encouraged to answer all items on the questionnaires. Participants will also be informed both verbally and in the youth consent form that they may terminate their participation in the study at any time.

This research has been cleared by the Ethics Committee of the Psychology Department. University of Windsor. Any concerns about the ethics or procedures of this investigations may be directed to: Dr. Stewart Page, Chair. Ethics Committee. Dept. of Psychology. University of Windsor. (519) 971-9489. ext. 2243.

If you have any questions about this study, the researchers can be contacted at the phone numbers listed below.

Thank you for your consideration.

Principal Investigator

Melanie D. Gallant. B.Sc., B.A. (Hons.)

Department of Psychology

University of Windsor

Tel. (519) 971-9489
Faculty Advisor

Kathryn D. Lafreniere. Ph.D.

Department of Psychology

University of Windsor

Tel. (519) 253-4232 ext. 2233

I have read the information attached and I consent to allow my son/daughter to participate in this project.

Signed:

Date: 
Appendix L

The instructions for this study will be adapted from the most recent update of Pennebaker's emotional disclosure writing paradigm (Pennebaker \& Graybeal, in press) and tailored for children and adolescents between the ages of 10 to 17.

\section{General Writing Instructions for all participants}

This study is an important project looking at writing. Over the next three days, you will be asked to keep a journal in which you will write about one of many different topics for 25 minutes each day. When you come each day you will be given your writing instructions. You will then be taken to a quiet room where you will be allowed to write. At the end of the 20 minutes, you will be told that you have 5 minutes left to write. When the 25 minutes are up you will be asked to answer some questions. After you are finished you will be free to leave.

The only rule I want you to remember is that you must write continuously for the entire time. If you run out of things to say, just repeat what you have already written. In your writing. don't worry about grammar, spelling, or sentence structure. Just write. Different people will be asked to write about different things. Because of this, please don't talk to anyone about what you have written during the experiment. Once the study is complete, you will be able to talk about your writing. Also, sometimes people feel a little sad or unhappy after writing. If this happens, it is completely normal. Most people say that these feelings go away in an hour or so. If at any time you feel upset or really sad, please come and tell me (principal investigator)

The only person who will read what you write is me (investigator). If I read something that makes me think that you are in any way being hurt then I will come and talk to you about what you wrote. I will also contact your parents to make them aware of my concerns. If what you 
wrote really upsets you and you feel that you need belp dealing with it then I will give you the names of people at Brentwood and in the community who can help. 
Appendix M

\section{Specific Participant and Control Condition Instruetions}

Participant instructions for the actual writing sessions will be based on a combination of Pennebaker's emotional disclosure writing paradigm (Pennebaker \& Graybeal, in press) and Reynolds et al. (2000), study on emotional disclosure in school children.

\section{Experimental Condition Instructions}

Participants assigned to the emotional disclosure condition will be given the following instructions:

\section{First Day of Writing}

Journals are designed to contain very private thoughts and feelings, which you may not have shared with anyone else. Over the next three days you are going to write your deepest thoughts and feelings about things that you have found stressful or sad. or made you feel angry or upset. In your writing, I want you to really write how you think and feel. You can write about anything that has happened in your life which you feht was very hard to deal with. Feel free to write as much as you want. Your writing will not be marked so do not worry about spelling or grammar. The important things is that you write about your deepest thoughts and feelings. Try to write as much as possible and if you run out of things to say, repeat what you have already written. Sometimes people feel a little sad or depressed after writing. If that happens it is completely normal. Most people find that these feelings go away in an hour or so. 


\section{Second Day of Writing}

Today I want you to continue writing about an event which has been really difficult or hard for you to deal with. It could be the same topic that you wrote about on the last day of writing or it could be something different. But today, I really want you to write about your very deepest thoughts and feelings.

\section{Third Day of Writing}

You have made it though two days of writing now. and today is the last one. In your writing today, I again want you to think about your deepest thoughts and feelings about an event which you found stressful or sad. or made you feel angry or upset. Remember. this is the last day, so if you want to talk about how the things your have been writing about make you feel right now you can. Make sure that you write about your deepest thoughts and emotions.

\section{Control Condition Instructions:}

Participants assigned to the event writing condition will be given the following instructions: What I would like you to write about over the next three days is how you use your time. Each day. I will give you different things to write about. When you write about these things I want you to describe them in detail. I am not interested in how you feel about what I ask you to write about. In today's writing I want you to start from when you got up this moming and describe in detail each task you accomplished until you went to bed. For example, you might describe how your alarm clock went off and what when you got out of bed. You could also write about the things you ate, where you went, which buildings or objects you passed 
by as you walked from place to place. The most important thing is to describe everything in detail.

\section{Second Day of Writing}

Today, I would like you to write about everything you have done since you woke up. Again. I want you to describe each event in full detail. This could involve describing what you ate for breakfast, lunch, and dinner.

\section{Third Day of Writing}

This is the last day of the experiment. In your writing today, I would like you to describe what you will be doing over the next week. Make sure that you describe each event you write about in full detail. 


\section{VITA AUCTORIS}

Melanie Gallant was born in 1975 in Windsor. Ontario. She graduated from Assumption High School in 1994. From there she went on to the University of Windsor where she concurrently obtained a B.Sc, in Biology and a B.A. in Psychology in 1999. She is currently a candidate for the Master's degree in Psychology at the University of Windsor and hopes to graduate in fall 2001. 